\title{
Use of Styrene as Sole Carbon Source by the Fungus Exophiala oligosperma: Optimization and Modeling of Biodegradation, Pathway Elucidation, and Cell Membrane Composition
}

Eldon R. Rene, Przemysław Bernat, Jerzy Długoński, Maria C. Veiga, Christian Kennes

Applied Biochemistry and Biotechnology, November 2012, Volume 168, Issue 6, pp 1351-1371

DOI 10.1007/s12010-012-9862-x

\begin{abstract}
Biodegradation of styrene by Exophiala sp. was tested at different initial concentrations (19.3-170.6 $\left.\mathrm{mg} \mathrm{l}^{-1}\right)$, $\mathrm{pH}$ (2.8-8.7), and temperatures (19.8-45.1 $\left.{ }^{\circ} \mathrm{C}\right)$, for $120 \mathrm{~h}$ according to a 23 full-factorial central composite design. The specific growth rate (SGR, per hour) and specific styrene utilization rate (SUR, milligrams of styrene per milligram of biomass per hour) values were used as the response variables for optimization purposes. The interactions between concentration and temperature $(\mathrm{P}=0.022)$, and $\mathrm{pH}$ and temperature $(\mathrm{P}=0.010)$ for $\mathrm{SGR}$, and interactions between concentration and temperature $(\mathrm{P}=0.012)$ for SUR were found to be statistically significant. The optimal values for achieving high SGR $\left(0.15 \mathrm{~h}^{-1}\right)$ and SUR (0.3622 mg styrene $\mathrm{mg}^{-1}$ biomass $\mathrm{h}^{-1}$ ) were calculated from the regression model equation. Those values are $\mathrm{C}_{0}=89.1$ $\mathrm{mg} \mathrm{l}^{-1}, \mathrm{pH}=5.4$, and $\mathrm{T}=31.5^{\circ} \mathrm{C}$ for SGR and $\mathrm{Co}=69.2 \mathrm{mgl}^{-1}, \mathrm{pH}=5.5$, and $\mathrm{T}=32.4$ ${ }^{\circ} \mathrm{C}$ for SUR. It was also observed that the Exophiala strain degrades styrene via phenylacetic acid, involving initial oxidation of the vinyl side chain. Besides, in the presence of styrene, changes in the fatty acids profile were also observed. It is hypothesized that an increasing amount of linoleic acid (18:2) may be involved in the protection of the fungus against toxic substrate.
\end{abstract}

\section{Keywords}

Biodegradation, filamentous fungi, Microbial growth, modeling, styrene degradation pathway, membrane fatty acids 


\section{Introduction}

Styrene, also known as vinyl benzene $\left(\mathrm{C}_{8} \mathrm{H}_{8}\right)$ is an important chemical derived from petroleum and natural gas by-products. Prolonged exposure to styrene vapors can cause health problems [1] . Bioprocesses represent an efficient, cost-effective, and promising option for the complete mineralization of volatile pollutants or even for their conversion to useful products [2, $\underline{3}]$. Studies pertaining to the isolation of styrene-degrading microorganisms were initiated by Sielicki et al. [4]. Those attempts were unsuccessful due to the inability of the isolated bacteria to tolerate high styrene concentrations (0.1 mol styrene $\left.\mathrm{l}^{-1}\right)$. Hartmans et al. [5] successfully isolated 14 strains of aerobic bacteria and two fungal strains that could grow with a styrene concentration of $0.5 \mathrm{mmol} \mathrm{l}^{-1}$. Most of the styrene biodegradation studies have focussed on aerobic bacteria, but very little effort has been made to understand the degradation pattern in fungi. Braun-Lüllemann et al. [6] studied gas-phase styrene degradation in batch liquid microcosms using the white-rot fungi Pleurotus ostreatus, Trametes versicolor, Bjerkandera adusta, and Phanerochaete chrysosporium, and reported that all fungi almost completely removed styrene at low and medium concentrations. In that study, the major styrene transformation products were identified as phenyl-1, 2-ethanediol, 2phenylethanol, and benzoic acid.

Kennes and Veiga [7] highlighted the potential advantages of stimulating fungal growth in biological waste gas treatment systems for the treatment of volatile organic compound (VOC)-polluted air. The biodegradation of non-oxygenated substituted benzene compounds is possible in some Exophiala species, which have been found in gas-phase biofilters treating toluene or styrene vapors [7]. However, hardly any detailed microbiological and kinetic studies have been published with such fungi. The specific substrate utilization rate (SUR) and enzyme activity of these fungi is expected to depend on the initial substrate concentration, $\mathrm{pH}$, and temperature. Estévez et al. [] compared the rates of toluene degradation in Exophiala oligosperma at temperatures between 23 and $40{ }^{\circ} \mathrm{C}$, and showed that the specific toluene utilization rate was relatively constant between 23 and $30^{\circ} \mathrm{C}$, but dropped significantly at $40^{\circ} \mathrm{C}$. Cox et al. [9] showed that Exophiala jeanselmei exhibited constant styrene oxidation rates between 22.5 and $33^{\circ} \mathrm{C}$, whereas a rapid decrease was observed at $42{ }^{\circ} \mathrm{C}$.

E. oligosperma was able to completely mineralize toluene in the $\mathrm{pH}$ range of 3.9-6.9 []. During continuous biotreatment of gas-phase styrene in a biofilter inoculated with the fungus Sporothrix variecibatus, high styrene elimination capacities $\left(336 \mathrm{~g}^{-3} \mathrm{~h}^{-1}\right)$ were reported under steady- and transient-state conditions, despite a drop in the $\mathrm{pH}$ of the filter bed from 5.9 to 3.5 [10]. Some microorganisms exhibit adaptation capabilities, enabling them to survive, and including, among others, changes in membrane lipid composition as a result of increased synthesis of saturated or unsaturated fatty acids [11-14]. Until now, there are no data available on the action of styrene on the fatty acids composition of microorganisms, involving those that are able to utilize that toxic pollutant. The alternation in the fatty acids profile results in permeability of the membrane and can also change the elimination rate of the toxic compound [14, 15]. Therefore, it appeared to be of interest to study possible changes in the fatty acids profile of Exophiala sp. growing on styrene.

Although several batch studies have reported the kinetics of fungal growth on different toxic substrates, many of them were not aimed at optimizing process parameters in a systematic way and were not purported to investigate the pathway of biodegradation. The priority therefore was to initiate studies with the following objectives: (1) to identify the optimum conditions for styrene removal and fungal growth, in terms of 
concentration, $\mathrm{pH}$, and temperature, by performing experiments designed with the help of response surface methodology (RSM) [16, 17]; (2) to model the biodegradation kinetics using specific growth rate and substrate utilization rate as the response variables; (3) to elucidate the styrene biodegradation pathway; and (4) to determine the cell membrane fatty acids composition of E. oligosperma when grown on styrene as the sole carbon source.

\section{Material and Methods}

\section{Media Composition}

The mineral salt medium used for maintaining the pure fungal culture in Petri dishes and for batch experiments had the following composition (per liter in distilled water): $0.5 \mathrm{~g} \mathrm{~K}_{2} \mathrm{HPO}_{4}, 0.1 \mathrm{~g} \mathrm{MgSO}_{4} \cdot 7 \mathrm{H}_{2} \mathrm{O}, 4.5 \mathrm{~g} \mathrm{KH}_{2} \mathrm{PO}_{4}, 2 \mathrm{~g} \mathrm{NH} 4 \mathrm{Cl}$, and $2 \mathrm{~mL}$ vitamins and trace minerals $[\underline{8}, \underline{18}]$. The medium was autoclaved at $120^{\circ} \mathrm{C}$ for $20 \mathrm{~min}$, before adding the filter-sterilized solutions of vitamins and trace minerals. The original $\mathrm{pH}$ of the medium was 5.9.

\section{Microorganism}

The fungus, E. oligosperma was isolated from a gas-phase biofilter operated at the University of La Coruña (Spain) and was identified at the Centraalbureau voor Schimmelcultures (The Netherlands) and was shown to grow on several benzene compounds. Stock cultures of the fungus were maintained on Petri dishes (15 g agar $\mathrm{l}^{-1}$ ), under ambient conditions, and were incubated in a desiccator in the presence of toluene vapors supplied as sole carbon source. One gram oxyacetylene was aseptically added to $1 \mathrm{l}$ sterilized agar medium to prevent bacterial growth.

\section{Batch Experiments}

E. oligosperma was cultured at $32.5^{\circ} \mathrm{C}$ for the elucidation of the metabolic pathway and at $30 \pm 0.5^{\circ} \mathrm{C}$ for the estimation of kinetic parameters and optimal growth conditions, with constant shaking at $175 \mathrm{rpm}$ under aerobic conditions in $110 \mathrm{ml}$ glass vials fitted with Viton septa and sealed airtight with aluminum caps. Five microliters of styrene was added to $9.7 \mathrm{ml}$ mineral salt medium containing both vitamins and trace minerals and $0.3 \mathrm{ml}$ of pregrown inoculum. This stock culture was grown until it reached an optical density of 0.8 at $600 \mathrm{~nm}$. Batch biodegradation tests (20 experiments) were carried out for $120 \mathrm{~h}$ according to the experimental design provided by response surface methodology (RSM). All the experiments were started with identical biomass concentrations $(3 \%, \mathrm{v} / \mathrm{v})$ that allowed the estimation of specific growth rate (SGR, per hour), and specific SUR (milligrams of styrene per milligram biomass per hour) profiles for a given set of conditions []‥ In order to perform these tests and to maintain the purity of the original fungus, different glass vials were used, maintaining similar experimental conditions and sacrificing one vial for each sample. By maintaining multiple vials for the same test condition, the possibility of contamination during sampling was completely avoided and the gas and liquid phase volumes remained constant. Styrene was added aseptically to these vials, to reach different initial gas phase concentrations. The biodegradation profile was monitored by measuring the gas phase consumption of styrene and the concentration in the liquid phase was then calculated from Henry's partition coefficient values at the respective temperatures [19]. The initial 
liquid-phase styrene concentrations varied slightly from the statistically designed values. Both non-inoculated media (blanks) and inoculated, yet autoclaved, vials (controls) for these 20 experiments were also prepared. This was done to assess abiotic styrene losses and degradation, and it was observed that the styrene concentrations remained unchanged in such vials. Biomass concentration (milligrams per liter), earlier correlated to $\mathrm{OD}$ at $600 \mathrm{~nm}$, was estimated by withdrawing a $1 \mathrm{ml}$ sample at different time intervals from the test vials. Gas-phase styrene concentration was also estimated periodically by withdrawing $2 \mathrm{ml}$ of headspace styrene using a gas-tight glass syringe.

\section{Analytical Methods}

A Crison model $507 \mathrm{pH}$ meter, connected to an Ingold electrode was used for measuring $\mathrm{pH}$. Biomass weight was estimated by measuring the optical density at $\lambda=600 \mathrm{~nm}$, and a standard calibration line was plotted based on the relationship between dry weight and OD. The absorbance of the liquid cultures, corresponding to the growth of the Exophiala sp. with styrene as the carbon source, was measured by using a UV-vis spectrophotometer (Hitachi, Model U-200, Pacisa \& Giralt, Madrid, Spain).

Gas-phase samples collected from vials were subjected to chromatographic analysis, on an HP 5890 gas chromatograph, using a $50 \mathrm{~m}$ TRACER column and a flame ionization detector. The flow rates were $30 \mathrm{ml} \mathrm{min}^{-1}$ for $\mathrm{H}_{2}$ and $300 \mathrm{ml} \mathrm{min}^{-1}$ for air. Helium was used as the carrier gas at a flow rate of $2 \mathrm{ml} \mathrm{min}^{-1}$. The temperatures at the gas chromatography (GC) injection, oven, and detection ports were 250, 120, and $250{ }^{\circ} \mathrm{C}$, respectively. $\mathrm{CO}_{2}$ was analyzed with a $\mathrm{HP} 5890$ gas chromatograph equipped with a thermal conductivity detector (TCD). The injection and oven temperatures were 90 and $25^{\circ} \mathrm{C}$, respectively, with the TCD set at $100^{\circ} \mathrm{C}$.

For the identification of metabolites from styrene metabolism, styrene biotransformation products were extracted from the medium with ethyl acetate and dried with sodium sulfate. Styrene oxide and phenylacetaldehyde were determined by gas chromatography (Hewlett Packard Model 6890) equipped with a 5973 Mass Detector. The separation was carried out in a capillary column Restek RTX-5MS $(60 \mathrm{~m} \times 250 \mu \mathrm{m} \times 0.25 \mu \mathrm{m})$. The column temperature was maintained at $50^{\circ} \mathrm{C}$ for $3 \mathrm{~min}$, then increased to $65^{\circ} \mathrm{C}$ at $10^{\circ} \mathrm{C} \mathrm{min}^{-1}$ and finally to $250{ }^{\circ} \mathrm{C}$ at $20^{\circ} \mathrm{C} \mathrm{min}^{-1}$ for $9 \mathrm{~min}$. Helium was used as the carrier gas at a flow rate of $1 \mathrm{ml} \mathrm{min}^{-1}$. Compound peaks of styrene oxide and phenylacetaldehyde were assigned by comparison with those obtained with the authentic standards.

The liquid chromatography-mass spectrometry (LC-MS)/MS analysis were carried out using an Agilent 1200 HPLC system coupled with a 3200 Q TRAP mass spectrometer (Applied Biosystems). Separation was performed on a Phenomenex Luna C18 column $(150 \times 50 \times 2.0 \mathrm{~mm}, 5 \mu \mathrm{m})$ using a flow rate of $0.5 \mathrm{ml} \mathrm{min}{ }^{-1}$. The mobile phases $\mathrm{A}$ and B were water (containing $5 \mathrm{mM}$ ammonium formate) and methanol (containing $5 \mathrm{mM}$ ammonium formate; 30:70 v/v), respectively. Sample elution was isocratic over $6 \mathrm{~min}$. The mass spectrometer used an electrospray interface in negative ionization mode. Multiple reaction monitoring (MRM) mode scan was performed. MRM uses the combination of a specific parent mass and a unique fragment ion to selectively monitor the compound to be quantified. The MRM transition pairs used for quantification of acids were chosen as: $\mathrm{m} / \mathrm{z} 134.9 \rightarrow 90.9$ for phenylacetic acid and $150.9 \rightarrow 106.9$ for 2 hydroxyphenylacetic acid. Major parameters used for analysis on the mass spectrometer included $25 \mathrm{psi}$ for curtain gas (CUR), 4,500 V for the ion spray voltage, $500{ }^{\circ} \mathrm{C}$ for source temperature, and 50 and $60{ }^{\circ} \mathrm{C}$ for ion source gas 1 and ion source gas 2 , 
respectively. Optimization of the compounds was performed by flow injection analysis, injecting individual standard solutions directly into the source.

\section{Phospholipids-Derived Fatty Acids Determination}

The stock culture utilizing styrene was prepared as mentioned above. Batch tests with the fungus utilizing styrene and/or glucose as sole carbon source (at initial concentrations of $170 \mathrm{mg}^{-1}$ ) were carried out for $72 \mathrm{~h}$ at a temperature of $32.5^{\circ} \mathrm{C}$. The biomass from a glass vial fitted with a Viton septum was separated from the media by centrifugation at $2,000 \times \mathrm{g}$ and then homogenized (MISONIX) with $20 \mathrm{ml}$ methanol. Then, $40 \mathrm{ml}$ chloroform was added and a sample was extracted. The organic phase was separated and fresh chloroform/methanol (2:1) was used. The organic phases were combined, dried over anhydrous $\mathrm{Na}_{2} \mathrm{SO}_{4}$ and the solvent was removed by evaporation. Total lipids were dissolved in chloroform $(1 \mathrm{ml})$ and fractionated by using a column $(25 \times 100 \mathrm{~mm})$ of silica gel $(0.5 \mathrm{~g})$ into neutral-, glyco- and phospholipids, with $4 \mathrm{ml}$ chloroform, acetone and methanol, respectively [20]. After evaporation of methanol, $5 \mathrm{ml}$ of methanol/toluene/sulfur acid (30:15:1, respectively) was added to each sample. After $18 \mathrm{~h}$ at $50{ }^{\circ} \mathrm{C}$, fatty acid methyl esters (FAMEs) were extracted twice with hexane $(4 \mathrm{ml})$. The extracts were dried with $\mathrm{Na}_{2} \mathrm{SO}_{4}$ and evaporated. FAMEs were analyzed by gas chromatography according to the procedure described elsewhere [13].

Double bond index (DBI) for C16 and C18 FA reflecting their unsaturation level was calculated from the percent values derived from gas chromatography data [21], according to the following equation:

$$
D B I=\left[\frac{[\{(\% \text { dienes } x 2)+(\% \text { monoenes })\}]}{\sum \% \text { saturatedfattyacids }}\right]
$$

\section{Experimental Design and Optimization of Parameters}

The conventional method of studying the biodegradation process, i.e., by maintaining the factors at an unspecified constant level, does not depict the combined effect of all the factors involved. This method is often laborious, time consuming, does not guarantee the determination of optimum conditions, and is unable to detect synergistic and/or antagonistic interactions between two or more factors [ $\underline{16}, \underline{17}]$. RSM is a collection of mathematical and statistical techniques useful for developing, improving, and optimizing processes, and can be used to evaluate the relative significance of several affecting factors even in the presence of complex interactions [16]. In the present study, the effect of initial styrene concentration, $\mathrm{pH}$, and temperature on the SGR (per hour), and specific SUR (milligrams of styrene per milligram of biomass per hour) by E. oligosperma was studied and optimized using RSM, and the results were statistically interpreted. The independent variables $(\mathrm{k}=3)$ were initial styrene concentration ( $\left.\mathrm{X}_{1}\right), \mathrm{pH}\left(\mathrm{X}_{2}\right)$, and temperature $\left(\mathrm{X}_{3}\right)$, while the SGR and SUR values were chosen as the response variables. The experimental range and levels of independent process variables are given in Table 1 . A $2^{\mathrm{k}}$ full-factorial experimental design with six replicates $\left(n_{o}\right)$ at the centerpoint, and thus a total of $20\left(2 k+2 k+n_{o}\right)$ experiments were performed in this study. The centerpoint was repeated six times, to give 5 degrees of freedom (DOF), to verify any change in the estimation procedure and as a measure of precision property [16]. The experimental design illustrated in Table $\underline{2}$ shows the coded and uncoded values of the individual variables, and the corresponding 
experimental and model predicted values of SGR and SUR, respectively. The variables were coded according to Eq. (2);

(2)

$$
X_{i}=\frac{\left(x_{i}-x_{o}\right)}{\Delta x}
$$

where, $\mathrm{X}_{\mathrm{i}}$ is the coded value of variable $\mathrm{i}, \mathrm{x}_{\mathrm{i}}$ is the dimensionless uncoded (actual) value of $X_{i}, X_{o}$ is the value of $X_{i}$ at the center point, and $\Delta \mathrm{x}$ is the step change between levels -1 and 0 .

Table 1

Experimental range and levels of independent process variables for styrene biodegradation

\begin{tabular}{|c|c|c|c|c|c|}
\hline \multirow{2}{*}{ Independent variable } & \multicolumn{5}{|c|}{ Range and level } \\
\hline & $-\boldsymbol{\alpha}$ & -1 & $\mathbf{0}^{\prime}$ & +1 & $+\alpha$ \\
\hline Concentration, $\mathrm{mg}^{-1}\left(\mathrm{X}_{1}\right)$ & 19.3 & 50 & 95 & 140 & 170.6 \\
\hline $\mathrm{pH}\left(\mathrm{X}_{2}\right)$ & 2.8 & 4 & 5.75 & 7.5 & 8.7 \\
\hline Temperature, ${ }^{\circ} \mathrm{C}\left(\mathrm{X}_{3}\right)$ & 19.8 & 25 & 32.5 & 40 & 45.1 \\
\hline
\end{tabular}

Table 2

Full factorial central composite design matrix for styrene removal

\begin{tabular}{|c|c|c|c|c|c|c|c|}
\hline \multirow{2}{*}{ Run order } & \multirow{2}{*}{$\mathrm{C}, \mathrm{mg} \mathrm{l}^{-1}\left(\mathrm{X}_{1}\right)$} & \multirow{2}{*}{ pH $\left(\mathrm{X}_{2}\right)$} & \multirow{2}{*}{$T,{ }^{\circ} \mathrm{C}\left(\mathrm{X}_{3}\right)$} & \multicolumn{2}{|c|}{ Experimental } & \multicolumn{2}{|c|}{ Predicted } \\
\hline & & & & SGR & SUR & SGR & SUR \\
\hline 1 & $-1(50)$ & $-1(4)$ & $-1(25)$ & 0.061 & 0.193 & 0.07 & 0.159 \\
\hline 2 & $+1(140)$ & $-1(4)$ & $-1(25)$ & 0.073 & 0.317 & 0.075 & 0.368 \\
\hline 3 & $-1(50)$ & $+1(7.5)$ & $-1(25)$ & 0.052 & 0.080 & 0.061 & 0.172 \\
\hline 4 & $+1(140)$ & $+1(7.5)$ & $-1(25)$ & 0.094 & 0.370 & 0.088 & 0.281 \\
\hline 5 & $-1(50)$ & $-1(4)$ & $+1(40)$ & 0.077 & 0.272 & 0.087 & 0.314 \\
\hline 6 & $+1(140)$ & $-1(4)$ & $+1(40)$ & 0.056 & 0.290 & 0.051 & 0.151 \\
\hline 7 & $-1(50)$ & +1 (7.5) & $+1(40)$ & 0.028 & 0.350 & 0.03 & 0.252 \\
\hline 8 & $+1(140)$ & $+1(7.5)$ & $+1(40)$ & 0.020 & 0.001 & 0.016 & 0.000 \\
\hline 9 & $-\alpha(19.32)$ & $0(5.75)$ & $0(32.5)$ & 0.160 & 0.439 & 0.145 & 0.415 \\
\hline 10 & $+\alpha(170.68)$ & $0(5.75)$ & $0(32.5)$ & 0.129 & 0.279 & 0.139 & 0.369 \\
\hline 11 & $0(95)$ & $-\alpha(2.81)$ & $0(32.5)$ & 0.046 & 0.143 & 0.04 & 0.168 \\
\hline 12 & $0(95)$ & $+\alpha(8.69)$ & $0(32.5)$ & 0.000 & 0.001 & 0.002 & 0.042 \\
\hline 13 & $0(95)$ & $0(5.75)$ & $-\alpha(19.89)$ & 0.060 & 0.251 & 0.054 & 0.217 \\
\hline 14 & $0(95)$ & $0(5.75)$ & $+\alpha(45.11)$ & 0.007 & 0.001 & 0.008 & 0.101 \\
\hline 15 & $0(95)$ & $0(5.75)$ & $0(32.5)$ & 0.131 & 0.370 & 0.149 & 0.36 \\
\hline 16 & $0(95)$ & $0(5.75)$ & $0(32.5)$ & 0.152 & 0.363 & 0.149 & 0.36 \\
\hline 17 & 0 (95) & $0(5.75)$ & $0(32.5)$ & 0.157 & 0.340 & 0.149 & 0.36 \\
\hline 18 & 0 (95) & $0(5.75)$ & $0(32.5)$ & 0.144 & 0.370 & 0.149 & 0.36 \\
\hline 19 & $0(95)$ & $0(5.75)$ & $0(32.5)$ & 0.152 & 0.363 & 0.149 & 0.36 \\
\hline 20 & $0(95)$ & $0(5.75)$ & $0(32.5)$ & 0.155 & 0.340 & 0.149 & 0.36 \\
\hline
\end{tabular}


C initial styrene concentration, $\mathrm{T}$ temperature, SGR $\mathrm{h}^{-1}$, SUR per milligram styrene removed per milligram biomass per hour

The results were fitted using the response surface regression procedure, using the following second-order polynomial equation (Eq. $\underline{3}$ ), and by analyzing the response surface and contour plots.

(3)

$$
Y=\beta_{o}+\sum_{i=1}^{k} \beta_{i} X_{i}+\sum_{i=1}^{k} \beta_{i i} X_{i 2}+\sum_{i} \sum_{j} \beta_{i j} X_{i} X_{j}
$$

where, $\mathrm{Y}$ is the predicted response, $\mathrm{k}$ is the number of variables, $\beta_{\mathrm{o}}$ is the offset term, $\beta_{\mathrm{i}}$ is the $i^{\text {th }}$ coefficient of linear effect, $\beta_{\text {ii }}$ is the $i^{\text {th }}$ coefficient of squared effect, $\beta_{i j}$ is the $\mathrm{ij}^{\text {th }}$ coefficient of interaction effect, and $\mathrm{X}_{\mathrm{i}}$ and $\mathrm{X}_{\mathrm{j}}$ are the coded values of independent variables $\mathrm{i}$ and $\mathrm{j}$, respectively.

Analysis of variance ( $\underline{\text { ANOVA }}$ ) was applied to estimate the main (linear) effects of independent variables and their potential interaction effects on the SGR and SUR during styrene biodegradation. The ANOVA table provides information on the following terms: degrees of freedom, sequential sum of squares, adjusted sum of squares, adjusted mean squares, Fischer's variance ratio, and probability value. The goodness of fit of the regression model and the significance of parameters estimates were determined through appropriate statistical methods. The results of this experimental design were analyzed and interpreted by MINITAB 16 (PA, USA) statistical software. For optimizing SGR and SUR simultaneously, the "Response Optimizer" function in the MINITAB software that adopts the desirability function method to optimize responses was used.

\section{Results and Discussion}

Batch Biodegradation Experiments: Effects of Styrene Concentration, $p H$, and Temperature

Biodegradation of styrene in batch experiments was carried out for $120 \mathrm{~h}$ with the Exophiala strain, at a liquid-phase concentration range of 19.3-170.6 mg $\mathrm{l}^{-1}$, corresponding to headspace styrene concentrations ranging between 2.7 and $26.1 \mathrm{~g} \mathrm{~m}^{-3}$. The initial concentrations used in this study were based exclusively on the biocatalyst's capability to degrade the compound, and by considering the solubility of styrene in water. The $\mathrm{pH}$ was varied from 2.8 to 8.7 , and temperature varied from 19.8 to $45.1^{\circ} \mathrm{C}$, following the scheme shown in Table 2 . Figure $\underline{1 \mathrm{a}-\mathrm{f}}$ shows styrene removal, biomass growth, and carbon dioxide generation profiles for some selected experimental runs. The growth of Exophiala sp. depended highly on the initial $\mathrm{pH}$ and temperature. Biomass growth was apparent after a short-lag phase $(<20 \mathrm{~h})$ for experimental runs 1,9 , 10, 13, and 15, in comparison to run 14 (Fig. 1e) which was carried out at a temperature of $45.1^{\circ} \mathrm{C}$. Styrene removal was also instantaneous, reaching $100 \%$ for run 9 (C o $\left.=19.3 \mathrm{mgl}^{-1}\right)$, and $>90 \%$ for runs 10 and $15\left(\mathrm{C}_{\mathrm{o}}=170.6\right.$ and $\left.95 \mathrm{mgl}^{-1}\right)$. Higher degradation rates were observed at lower initial concentrations. Indeed, at fixed $\mathrm{pH}$ (5.75) and temperature $\left(32.5^{\circ} \mathrm{C}\right)$, low concentrations were completely removed at higher rates, in $<50 \mathrm{~h}$, compared to high concentrations which were only $90 \%$ removed in $120 \mathrm{~h}$. This also demonstrates the ability of the fungus to completely mineralize styrene and use it as single carbon and energy source. Styrene removal remained low $(<25 \%)$ for runs $7,8,11,12$, and 14 , reaching hardly $5 \%$ for run 12 and $8 \%$ for run 14 , which were basically insignificant. Runs 12 and 14 were carried out at the highest $\mathrm{pH}$ 
(8.69) and temperature $\left(45.1^{\circ} \mathrm{C}\right)$, by maintaining the styrene concentration at $95 \mathrm{mg} \mathrm{l}^{-1}$, suggesting that the fungus is inactive at such high $\mathrm{pH}$ and temperature. For all other runs, styrene removal varied between 42 and $63 \%$, confirming the influence of pH and temperature on the biodegradation of styrene by Exophiala sp.

a
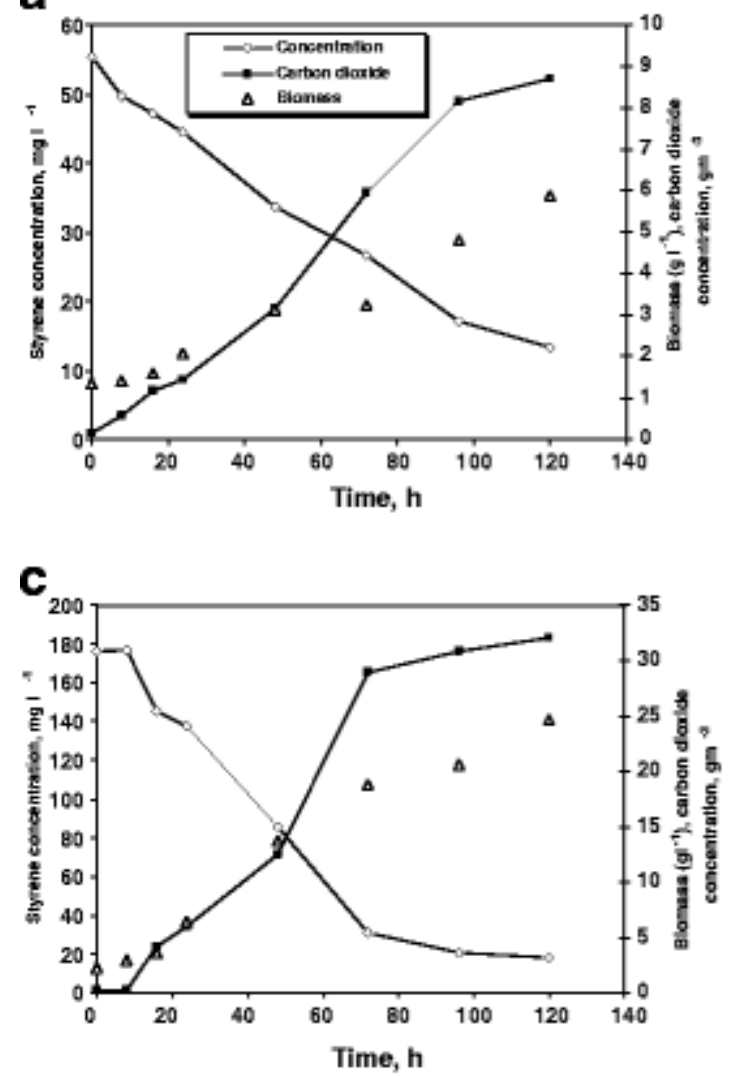

e

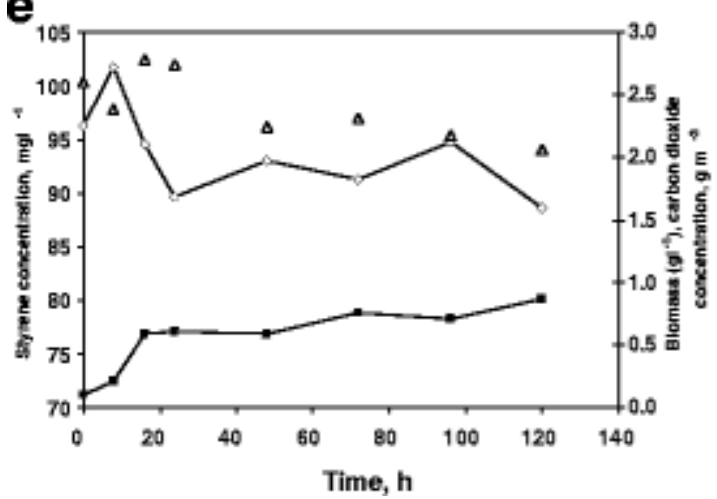

b

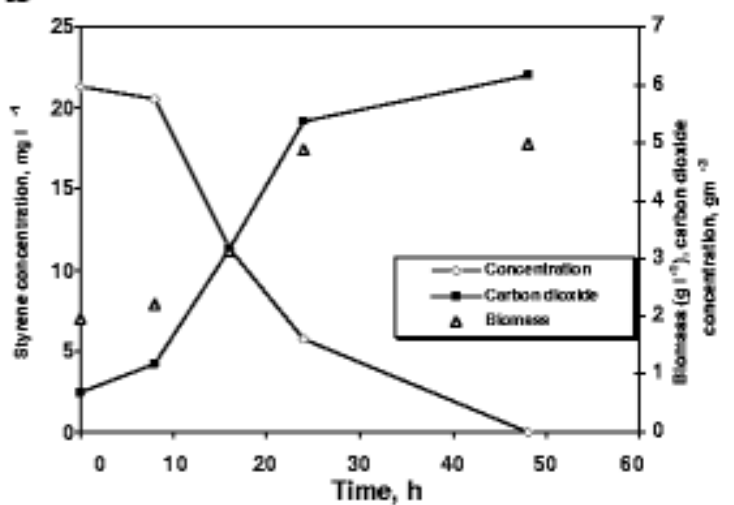

d

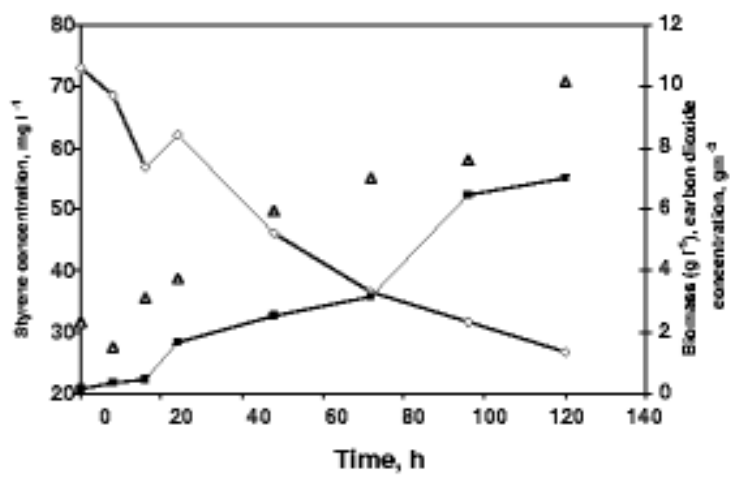

f

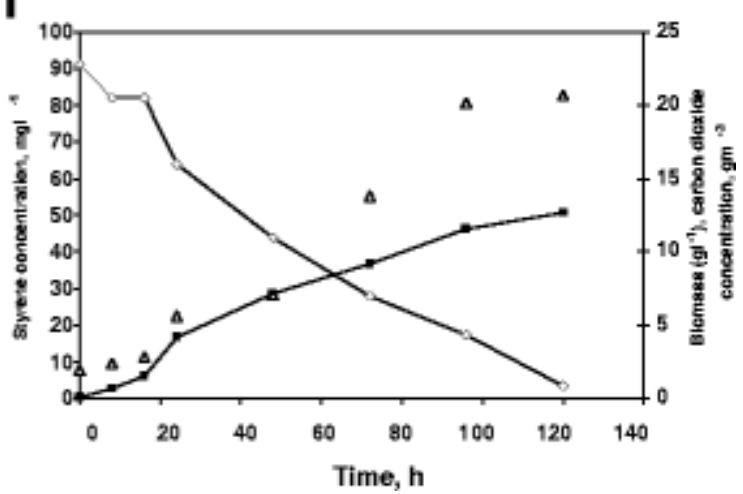

Fig. 1

Styrene removal, biomass growth, and carbon dioxide concentration profiles at different experimental conditions: a run $1, \mathrm{C}_{0}{ }_{0}=50 \mathrm{mg} \mathrm{l}^{-1}, \mathrm{pH}=4, \mathrm{~T}=25^{\circ} \mathrm{C} ; \mathrm{b}$ run $9, \mathrm{C}_{\mathrm{o}}=19.32 \mathrm{mg} \mathrm{l}^{-1}, \mathrm{pH}=5.75$, $\mathrm{T}=32.5^{\circ} \mathrm{C}$; c run $10, \mathrm{C}_{\mathrm{o}}=170.68 \mathrm{mg} \mathrm{l}^{-1}, \mathrm{pH}=5.75, \mathrm{~T}=32.5^{\circ} \mathrm{C} ; \mathrm{d}$ run $13, \mathrm{C}_{\mathrm{o}}=95 \mathrm{mg} \mathrm{l^{-1 }}, \mathrm{pH}=5.75$, $\mathrm{T}=19.89^{\circ} \mathrm{C}$; e run $14, \mathrm{C}_{\mathrm{o}}=95 \mathrm{mg} \mathrm{l}^{-1}, \mathrm{pH}=5.75, \mathrm{~T}=45.11^{\circ} \mathrm{C}$, and $\mathrm{f}$ run $15, \mathrm{C}_{\mathrm{o}}=95 \mathrm{mg} \mathrm{l}^{-1}, \mathrm{pH}=5.75$, $\mathrm{T}=32.5^{\circ} \mathrm{C}$

Regarding carbon dioxide profiles, for complete oxidation of styrene to $\mathrm{CO}_{2}$ and water, the ratio of mass $\mathrm{CO}_{2}$ produced to the amount of styrene consumed should be 3.4, according to the following stoichiometric equation, neglecting biomass growth (Eq. 4 ):

$$
\mathrm{C}_{8} \mathrm{H}_{8}+10 \mathrm{O}_{2} \rightarrow 8 \mathrm{CO}_{2}+4 \mathrm{H}_{2} \mathrm{O}
$$


However, when biomass growth is taken into account, with ammonium chloride as nitrogen source, then $1.27 \mathrm{~g} \mathrm{CO}_{2}$ should be generated for each gram styrene degraded, which can be represented by Eq. (ㅁ),

(5)

$$
\mathrm{C}_{8} \mathrm{H}_{8}+5 \mathrm{O}_{2}+\mathrm{NH}_{4} \mathrm{Cl} \rightarrow 3 \mathrm{CO}_{2}+\mathrm{C}_{5} \mathrm{H}_{7} \mathrm{NO}_{2}+\mathrm{HCl}+2 \mathrm{H}_{2} \mathrm{O}
$$

In this study, the ratio of $\mathrm{CO}_{2}$ produced to the amount styrene removed was either somewhat greater than (run 9) or in some instances lower than (run 10) the theoretical amount of $\mathrm{CO}_{2}$ expected from Eq. $\underline{5}$. In cases where the stoichiometric criterion is not exactly met, the unaccounted $\mathrm{CO}_{2}$ could have accumulated in the aqueous phase, depending on the $\mathrm{pH}$ and temperature, in the form of $\mathrm{HCO}^{-}, \mathrm{H}_{2} \mathrm{CO}_{3}$, or $\mathrm{CO}_{3}{ }^{2-}$.

Additionally, the SUR, a parameter used to describe the extent of pollutant removal using a particular microbial species, by taking into account biomass concentration and time, was also estimated. Under the set of experimental conditions tested (Table 2), the SUR was found to vary between 0.001 and $0.439 \mathrm{mg}$ styrene $\mathrm{mg}^{-1}$ biomass $\mathrm{h}^{-1}$. Runs 8 , 12 , and 14 showed the lowest SUR $\left(0.001 \mathrm{mg}\right.$ styrene $\mathrm{mg}^{-1}$ biomass $\left.\mathrm{h}^{-1}\right)$, where biomass growth was severely affected or inhibited by both $\mathrm{pH}$ and temperature, leading to negligible removal of styrene. Similarly, the SGR were also very low or negligible in these runs, $<0.02 \mathrm{~h}^{-1}$, when compared to the maximum value of $0.16 \mathrm{~h}^{-1}$ in run 9 .

\section{Main Effects of Process Parameters}

The main effects plot for SGR and SUR showed a very complex behavior depending on the initial styrene concentration, $\mathrm{pH}$, and temperature, as observed in Figs. $\underline{2}$ and $\underline{3}$. Figure 2 could be interpreted as follows: (1) increasing the concentration of styrene from low $\left(19.3 \mathrm{mg} \mathrm{l}^{-1}\right)$ to high levels $\left(170.6 \mathrm{mg} \mathrm{l}^{-1}\right)$, decreased the specific growth rate from an initial value of 0.16 to $0.04 \mathrm{~h}^{-1}$ at $50 \mathrm{mgl}^{-1}$, and for higher concentrations $\left(>50-170.6 \mathrm{mgl}^{-1}\right.$ ), the specific growth rate fluctuated between 0.05 and $0.12 \mathrm{~h}^{-1}$; (2) the SGR increased with an increase in $\mathrm{pH}$, reaching a maximum of $\sim 0.12 \mathrm{~h}^{-1}$ at the centerpoint level ( $\mathrm{pH}$ 5.75), and then decreased with a further increase in $\mathrm{pH}$ from 5.75 to the inhibitory $\mathrm{pH}$ value of 8.69; and (3) increasing the temperature from 19.8 to $32.5^{\circ} \mathrm{C}$ increased the SGR, but beyond that temperature, the SGR decreased drastically, reaching inhibition at $45^{\circ} \mathrm{C}$. The variations of SGR with $\mathrm{pH}$ and temperature, i.e., the increasing and decreasing trend after reaching a maximum, allows defining an optimum range of values for these two factors allowing reaching high SGR. However, as seen in Fig. 3 , the main effects plot for SUR was slightly different from those envisioned for SGR. At low styrene concentrations, the SUR was $>0.4 \mathrm{mg}$ styrene $\mathrm{mg}^{-1}$ biomass $^{-1}$ and the SUR almost remained constant when the styrene concentration was increased from 50 to $170 \mathrm{mg}^{-1}$. A similar trend was also observed for temperature effects, and the SUR values only decreased significantly beyond $40{ }^{\circ} \mathrm{C}$, remaining otherwise almost constant over a wide range of temperatures $\left(19.8-40^{\circ} \mathrm{C}\right)$. Rajasekaran and Maheswari [22] showed that the respiration rate of fungal mycelia can vary over a rather wide range, depending on the temperature, and thermophilic fungi like Thermomyces lanuginosus and Penicillium duponti exhibit maximum rates at $50{ }^{\circ} \mathrm{C}$. Most of the previous studies on VOC treatment using fungi were performed at temperatures between 20 and $40{ }^{\circ} \mathrm{C}$, yet some studies have reported that the substrate utilization rates dropped significantly beyond $40^{\circ} \mathrm{C}$, and that the fungi were inactive above such temperature $[\underline{8}, \underline{9}]$. Only a few studies have reported continuous thermophilic biofiltration of hydrophobic VOCs like BTEX and $\alpha$-pinene, at temperatures $>45{ }^{\circ} \mathrm{C}$ [23-25]. Wang et al. [26] reported that the optimum temperatures for fungal growth $\left(37^{\circ} \mathrm{C}\right)$ and degradation of gas phase chlorobenzene $\left(28^{\circ} \mathrm{C}\right)$ were different due to the 
occurrence of different enzyme systems, i.e., lignin peroxidases, manganese peroxidises, and laccase in P. chrysosporium. The Exophiala sp. used in this study was able to tolerate temperatures up to a threshold value of about $40{ }^{\circ} \mathrm{C}$.

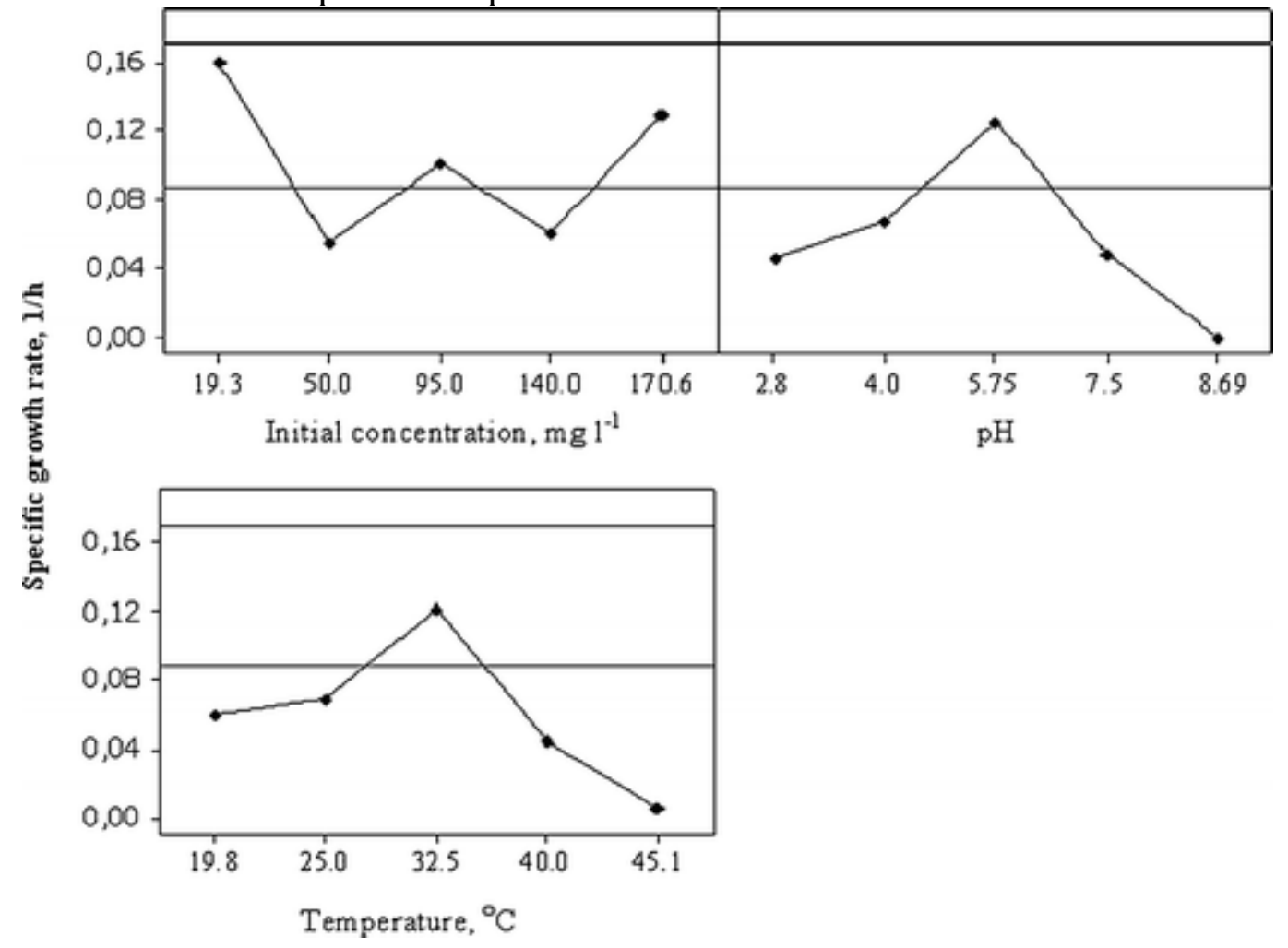

Fig. 2

Main effects of process parameters on the SGR during styrene degradation for all the experimental runs. Range of parameters: initial styrene concentration, 19.3-170 $\mathrm{mg} \mathrm{l}^{-1}$; $\mathrm{pH}, 2.8-8.7$; and temperature, 19.8$45.1^{\circ} \mathrm{C}$

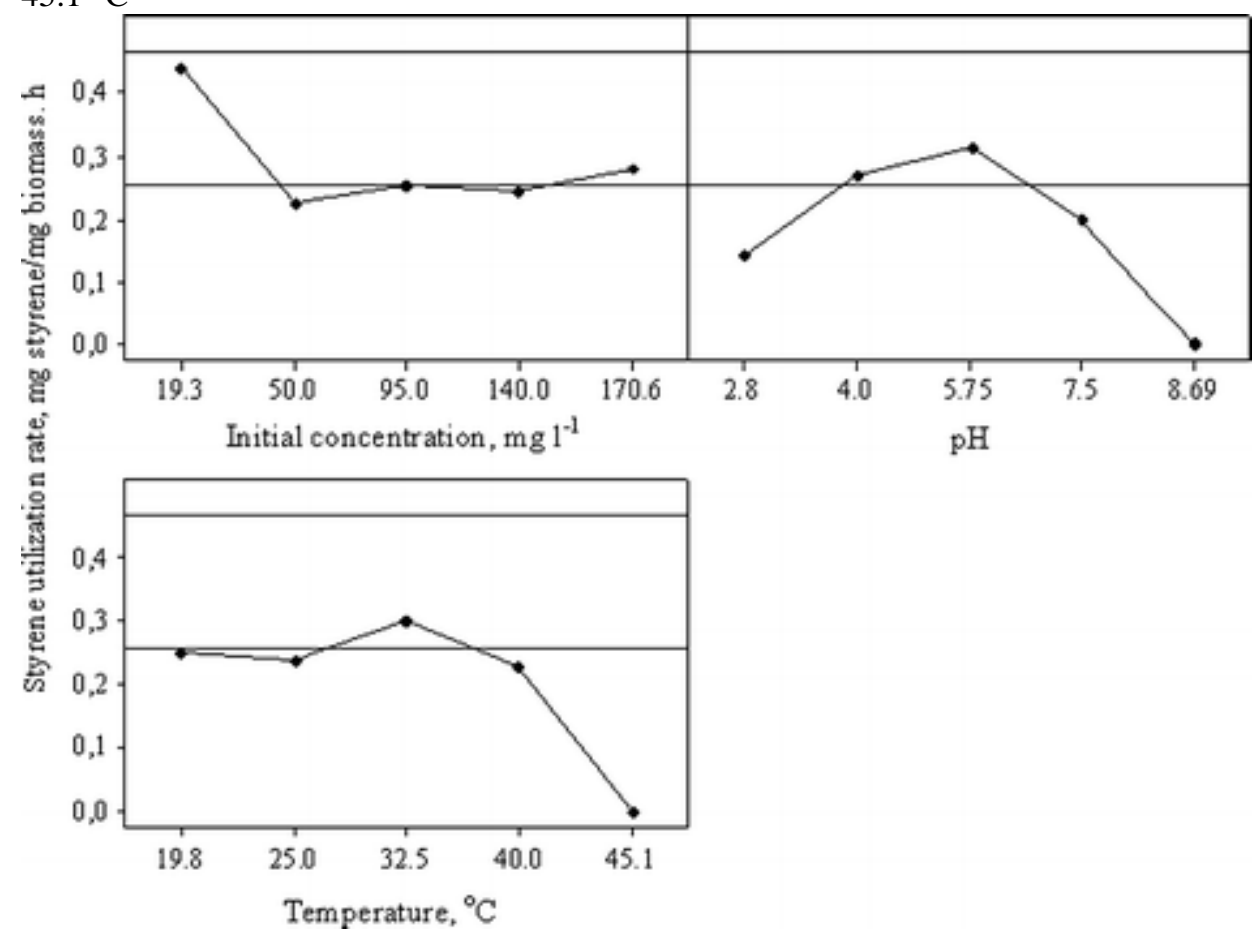

Fig. 3

Main effects of process parameters on the SUR during styrene degradation for all the experimental runs. Range of parameters: initial styrene concentration, $19.3-170 \mathrm{mg} \mathrm{l}^{-1}$; $\mathrm{pH}, 2.8-8.7$; and temperature, 19.8$45.1^{\circ} \mathrm{C}$ 
The influence of $\mathrm{pH}$ was more pronounced, and the maximum SUR was observed at a $\mathrm{pH}$ of 5.75 (0.3 mg styrene $\mathrm{mg}^{-1}$ biomass $\mathrm{h}^{-1}$ ). These profiles of SGR and SUR and their dependency on $\mathrm{pH}$ suggest that at both low (2.8) and high levels (8.6), the biodegrading capability of the fungus was extremely limited or even inhibited. Although it has been reported that fungi can tolerate acidic $\mathrm{pH}$ conditions, very low pHs are not optimal [27]. Modification in membrane permeability, lipid solubilization, and adsorption and inactivation of proteins has been reported as factors contributing to the loss of activity leading to growth-limiting/inhibiting conditions [28]. For some fungi, $\mathrm{pH}$ other than their optimum can cause a change in the ionic charges of the acidic and basic groups and therefore mutate the $\mathrm{R}$ groups in the amino acids which disrupt the ionic bonding, leading to modifications in the enzyme shape and positioning of the active biodegradation sites. Bhattacharya and Banerjee [29] reported that the efficiency of 2,4-dichlorophenol removal by the fungus Pleurotus sp. was at its maximum ( $>95 \%)$ at temperature $>37^{\circ} \mathrm{C}$, and $\mathrm{pH}$ values between 5.5 and 6 . The authors attributed the better fungal performance to the stability of the laccase enzymes in that $\mathrm{pH}$ range, and the enzymes were largely stabilized by weak interactions such as hydrogen bonds and van der Waals forces. Fungi like Exophiala sp. have septate hyphae which bear conidiogenous cells (annelides) and usually ellipsoidal conidia $(1-3 \times 3-6 \mu \mathrm{m})$ are produced from the annelids [30]. Dix and Webster [31] showed that $\mathrm{pH}$ has little direct effect on fungal metabolism due to the buffering system in septate hyphae, but may influence the ionization of salts in solution and the permeability of the plasmalemma of the hyphae.

The data from our study collectively display antagonistic and synergistic effects on SGR and SUR values, thereby affecting styrene removal, and these effects depended on levels of the initial settings of concentration, $\mathrm{pH}$ and temperature $(-\alpha,-1,0,+1$, and $+\alpha$ ). These results produced main, squared, and interaction effects, which will be statistically interpreted in the next section of this paper.

\section{Analysis of Variance and Regression Model Equation}

The experimental results were analyzed in the form of ANOVA by using SGR and SUR as the response variables (Table $\underline{3}$ ). ANOVA is a statistical technique that subdivides the total variation in a set of data into component parts associated with specific sources of variation for the purpose of testing hypotheses on the different parameters of the model [32]. The statistical significance of the ratio of mean square due to regression and mean square due to residual error was tested using ANOVA. As seen in Table $\underline{3}$, the $\mathrm{F}$ statistics values for SGR were higher than those observed for SUR. The P values were used to judge whether $F$ statistics is large enough to indicate statistical significance [33]. Thus, high $\mathrm{F}_{\text {statistics }}$ and low $\mathrm{P}$ values $(<0.05)$ indicate that the effect is significant at the $95 \%$ confidence level [34]. The $\mathrm{P}$ values for the linear, squared (quadratic), and interaction effects were $<0.05$ for SGR, while only the squared effects for SUR were found to be statistically significant. Besides, the $\mathrm{F}$ statistics values of regression (53.52 and 4.36) for SGR and SUR were less than the maximum $F$ statistics of the effects (141.93 and 7.94) which indicates that the second-order polynomial model would produce some errors while representing the relationship between the process parameters and the response variable. The residual error in Table $\underline{3}$ indicates the amount of variation in the response data left unexplained by the model. 
Table 3

Analysis of variance (ANOVA) for SGR and SUR during styrene biodegradation

\begin{tabular}{|c|c|c|c|c|c|c|c|c|c|c|c|c|}
\hline \multirow[b]{2}{*}{ Source } & \multicolumn{2}{|l|}{ DF } & \multicolumn{2}{|c|}{ Seq SS } & \multicolumn{2}{|c|}{ Adj MS } & \multicolumn{2}{|c|}{$F_{\text {statistics }}$} & \multicolumn{2}{|l|}{$\mathbf{P}$} & \multicolumn{2}{|l|}{$\mathbf{R}^{2}$} \\
\hline & $\begin{array}{l}\text { SG } \\
\text { R }\end{array}$ & $\begin{array}{l}\text { SU } \\
\text { R }\end{array}$ & SGR & SUR & SGR & SUR & SGR & $\begin{array}{l}\text { SU } \\
\mathbf{R}\end{array}$ & SGR & SUR & $\begin{array}{l}\text { SG } \\
\text { R }\end{array}$ & $\begin{array}{l}\text { SU } \\
\mathbf{R}\end{array}$ \\
\hline Regression & 9 & 9 & $\begin{array}{l}0.05 \\
6\end{array}$ & $\begin{array}{l}0.29 \\
2\end{array}$ & $\begin{array}{l}0.00 \\
6\end{array}$ & $\begin{array}{l}0.03 \\
2\end{array}$ & 53.52 & 4.36 & 0.000 & 0.015 & 0.99 & 0.89 \\
\hline Linear & 3 & 3 & $\begin{array}{l}0.00 \\
4\end{array}$ & $\begin{array}{l}0.03 \\
7\end{array}$ & $\begin{array}{l}0.00 \\
1\end{array}$ & $\begin{array}{l}0.01 \\
2\end{array}$ & 12.20 & 1.69 & $\begin{array}{l}<0.0 \\
5\end{array}$ & 0.232 & & \\
\hline Square & 3 & 3 & $\begin{array}{l}0.05 \\
0\end{array}$ & $\begin{array}{l}0.17 \\
7\end{array}$ & $\begin{array}{l}0.01 \\
6\end{array}$ & $\begin{array}{l}0.05 \\
9\end{array}$ & $\begin{array}{l}141.9 \\
3\end{array}$ & 7.94 & $\begin{array}{l}<0.0 \\
5\end{array}$ & $<0.05$ & & \\
\hline $\begin{array}{l}\text { Interactio } \\
\mathrm{n}\end{array}$ & 3 & 3 & $\begin{array}{l}0.00 \\
2\end{array}$ & $\begin{array}{l}0.07 \\
7\end{array}$ & $\begin{array}{l}0.00 \\
1\end{array}$ & $\begin{array}{l}0.02 \\
5\end{array}$ & 6.43 & 3.46 & $\begin{array}{l}<0.0 \\
5\end{array}$ & 0.059 & & \\
\hline $\begin{array}{l}\text { Residual } \\
\text { error }\end{array}$ & 10 & 10 & $\begin{array}{l}0.00 \\
1\end{array}$ & $\begin{array}{l}0.07 \\
4\end{array}$ & $\begin{array}{l}0.00 \\
1\end{array}$ & $\begin{array}{l}0.00 \\
7\end{array}$ & & & & & & \\
\hline Lack of fit & 5 & 5 & $\begin{array}{l}0.00 \\
1\end{array}$ & $\begin{array}{l}0.07 \\
3\end{array}$ & $\begin{array}{l}0.00 \\
1\end{array}$ & $\begin{array}{l}0.01 \\
4\end{array}$ & 1.53 & 74.7 & 0.327 & $\begin{array}{l}<0.00 \\
5\end{array}$ & & \\
\hline Pure error & 5 & 5 & $\begin{array}{l}0.00 \\
1\end{array}$ & $\begin{array}{l}0.00 \\
1\end{array}$ & $\begin{array}{l}0.00 \\
1\end{array}$ & $\begin{array}{l}0.00 \\
1\end{array}$ & & & & & & \\
\hline Total & 19 & 19 & $\begin{array}{l}0.05 \\
7\end{array}$ & $\begin{array}{l}0.36 \\
7\end{array}$ & & & & & & & & \\
\hline
\end{tabular}

DF degrees of freedom, Seq SS sequential sum of squares, Adj SS adjusted sum of squares, Adj MS adjusted mean squares, $\mathrm{F}$ statistics Fischer's variance ratio, P probability value

Furthermore, Student's t test was used to determine the significance of the regression coefficients of the parameters. The corresponding $\mathrm{P}$ values were used as a tool to check the significance of each of the interactions among the variables, which in turn may indicate the patterns of interactions between the variables. The regression coefficient, $t$ and $\mathrm{P}$ values for all the linear, squared, and interaction effects of the parameter are given in Table $\underline{4}$, for SGR and SUR, respectively. The regression model equations for SGR and SUR are given in Eqs. (ㅁ) and (ㅁ), respectively.

$S G R: Y_{1}=0.1486-0.002 X_{1}-0.011 X_{2}-0.014 X_{3}-0.002 X_{12}-0.045 X_{22}$

$$
-0.042 X_{32}+0.005 X_{1} \times X_{2}-0.01 X_{1} \times X_{3}-0.012 X_{2} \times X_{3}
$$

SUR: $Y 2=0.356-0.014 X_{1}-0.037 X_{2}-0.034 X_{3}+0.013 X_{12}-0.089 X_{22}-0.07 X_{32}$

$$
-0.025 X_{1} \times X_{2}-0.093 X_{1} \times X_{3}-0.019 X_{2} \times X_{3}
$$


Table 4

Estimated regression coefficients and corresponding $\mathrm{t}$ and P values for SGR and SUR during styrene biodegradation

\begin{tabular}{|l|l|l|l|l|l|l|l|l|}
\hline Term & \multicolumn{1}{l}{ Coefficient } & \multicolumn{2}{l|}{ SE coefficient } & t & \multicolumn{2}{l|}{ P } \\
& SGR & SUR & SGR & SUR & SGR & SUR & SGR & SUR \\
\hline Constant & 0.149 & 0.356 & 0.004 & 0.035 & 33.614 & 10.100 & 0.000 & 0.000 \\
\hline $\mathrm{X}_{1}$ & -0.002 & -0.014 & 0.003 & 0.023 & -0.677 & -0.584 & 0.514 & 0.572 \\
\hline $\mathrm{X}_{2}$ & -0.011 & -0.037 & 0.003 & 0.023 & -3.753 & -1.600 & $<0.05$ & 0.141 \\
\hline $\mathrm{X}_{3}$ & -0.014 & -0.034 & 0.003 & 0.023 & -4.695 & -1.470 & $<0.05$ & 0.172 \\
\hline $\mathrm{X}_{1}{ }^{2}$ & -0.002 & 0.013 & 0.003 & 0.023 & -0.823 & 0.568 & 0.430 & 0.583 \\
\hline $\mathrm{X}_{2}{ }^{2}$ & -0.045 & -0.089 & 0.003 & 0.023 & -15.863 & -3.896 & $<0.05$ & $<0.05$ \\
\hline $\mathrm{X}_{3}{ }^{2}$ & -0.042 & -0.07 & 0.003 & 0.023 & -14.563 & -3.056 & $<0.05$ & $<0.05$ \\
\hline $\mathrm{X}_{1} \times \mathrm{X}_{2}$ & 0.005 & -0.025 & 0.004 & 0.031 & 1.402 & -0.824 & 0.191 & 0.429 \\
\hline $\mathrm{X}_{1} \times \mathrm{X}_{3}$ & -0.010 & -0.093 & 0.004 & 0.031 & -2.707 & -3.051 & $<0.05$ & $<0.05$ \\
\hline $\mathrm{X}_{2} \times \mathrm{X}_{3}$ & -0.012 & -0.019 & 0.004 & 0.031 & -3.163 & -0.621 & $<0.05$ & 0.549 \\
\hline
\end{tabular}

From Table 4 , it is evident that the coefficient for the linear effects due to $\mathrm{pH}\left(\mathrm{X}_{2}\right)$ and temperature $\left(\mathrm{X}_{3}\right)$ for SGR showed less $\mathrm{P}$ values $(\mathrm{P}=0.004,0.001)$, indicating that these effects were more pronounced for SGR than for SUR. Among the squared (quadratic) effects, $\mathrm{pH}\left(\mathrm{X}_{2}{ }^{2}\right)$, and temperature $\left(\mathrm{X}_{3}{ }^{2}\right)$ were significant for both SGR and SUR with P values of $0.000,0.000$ (SGR) and 0.003, 0.012 (SUR), respectively. The coefficients of interaction effects appeared to be significant between concentration and temperature $(\mathrm{P}=0.022)$, and $\mathrm{pH}$ and temperature $(\mathrm{P}=0.010)$ for $\mathrm{SGR}$, and between concentration and temperature $(\mathrm{P}=0.012)$ for SUR. All other interaction effects were found to be insignificant at the $95 \%$ confidence limit $(\mathrm{P}>0.05)$. The positive terms of the coefficients given in Table $\underline{4}$ indicate a direct effect on the SGR and SUR values, and subsequently the removal of styrene. Except for the interactions between concentration and $\mathrm{pH}(0.005)$ for SGR and concentration and concentration (0.013) for SUR, all other coefficients showed an indirect effect on the SGR and SUR values. The experimental and predicted values of SGR and SUR are shown in Table $\underline{2}$. The predicted values were not statistically different from their experimental counterparts, yielding coefficient of determination $\left(\mathrm{R}^{2}\right.$ ) values of 0.99 and 0.89 , respectively (Table $\underline{3}$ ). Thus, only less that $1.1 \%$ variation in SGR and $11 \%$ in the case of SUR, was not statistically explained by the model equation, reflecting the goodness of fit of the regression model to analyze trends in the responses. Though the value of $\mathrm{R}^{2}=0.89$ would be considered low in applied statistics, it can be accepted due to complex interactions observed between fungal growth-styrene utilization-pH-temperature, which could not be reasoned by the model equation. These variations in the model predictions were already symptomatically highlighted in Table $\underline{3}$, when $\mathrm{F}$ statistics values of regression (53.52 and 4.36) were less than the $F$ statistics from the effects. It is noteworthy to remind here that such observations on the significance of different statistical terms, the main effects and interactions among different process parameters, i.e., styrene concentration, $\mathrm{pH}$, and temperature, would go unnoticed if experiments were to be carried out by conventional methods. 


\section{Response Surface Optimization}

The response surface plots (Figs. $\underline{4 a}$ and $c, 5 a$ and $c$, and $\underline{6 a}$ and $c$ ) obtained from the software provide a three dimensional view of the SGR and SUR surface over different combinations of independent variables. The contour plots (Figs. $\underline{4 b}$ and d, $\underline{5 b}$ and d , and $\underline{6 \mathrm{~b} \text { and } \mathrm{d}}$ ) are represented as a function of two factors at a time, holding other factors at a fixed level (centerpoint " 0 ”). The effect of $\mathrm{pH}$ and temperature on the SGR and SUR, holding the styrene concentration at a constant value $\left(95 \mathrm{mg} \mathrm{l}^{-1}\right)$ is illustrated in Fig. $4 \mathrm{a}-$ d. The maximum predicted SGR or SUR is indicated by the smallest ellipse that confines within the contour plot. This type of plot passes through the steepest ascent of SGR or SUR, and the optimum operating conditions and in direction of maximum decline of the response with respect to increasing or decreasing values of the independent variable ( $\mathrm{pH}$ and temperature). It is also evident from the surface plots (Fig. $\underline{4 a-c}$ ) that at low $(-\alpha)$ and high $(+\alpha)$ levels of $\mathrm{pH}$ and temperature, both the SGR and SUR were minimal, and there was a narrow region where neither an increasing nor a decreasing trend in SGR and SUR was noticed. This type of response surface and contour (elliptical) plots suggests the definite existence of optimum conditions, and the surface confined in the smallest curve can be used to predict the maximum response in the process [35]. As shown in Table $\underline{3}$ (ANOVA), these interactions were highly significant with $\mathrm{P}<0.05$. The nature of response surface plots also depends on the sign and magnitude of the coefficients for SGR and SUR, as shown in Table $\underline{4}$. The squared and the interaction effects play a vital role, and a formal analysis can shed more light on the nature of response surfaces. Figures $\underline{5}$ and $\underline{6}$ reveal rising ridge (linear in one direction and curvilinear in the other) and saddle type contour plots for SGR and SUR, obtained during concentration and temperature $(\mathrm{pH} 5.75)$, and concentration and $\mathrm{pH}$ interactions $\left(\mathrm{T}=32.5^{\circ} \mathrm{C}\right)$. These types of contour plots produce stationary points that have the maximum estimated response or an approximate maximum on a line within the design region [36]. From Fig. $\underline{5 a}$, it is evident that the SGR is largely affected by temperature variations and at constant temperatures, when the concentration was increased from $-\alpha$ to $+\alpha$ levels, the SGR remained stationary, reaching maximum values at $\sim 32.5^{\circ} \mathrm{C}$. A nearly similar behavior was also seen for concentration and $\mathrm{pH}$ on SGR (Fig. 6a). However, for the surface plot depicting concentration and temperature on SUR, the following observations were made: (1) when the styrene concentration was low $(-\alpha)$, an increase in temperature from low $\left(19.8^{\circ} \mathrm{C}\right)$ to high $\left(40^{\circ} \mathrm{C}\right)$ levels increased the SUR significantly; and (2) when the styrene concentration was high $(+\alpha)$, an increase in temperature caused the SUR to decrease from an already high value $(0.4 \mathrm{mg}$ styrene $\mathrm{mg}^{-1}$ biomass $\mathrm{h}^{-1}$ ) to lower values. However, within the range of styrene concentrations tested, no significant interactions were produced between concentration and $\mathrm{pH}$ as evident from their high P values for SGR (0.191) and SUR (0.429). On the other hand, the quadratic effects due to concentration $\left(\mathrm{X}_{1}{ }^{2}\right)$ were also insignificant (P $=0.430,0.583)$, indicating that the SGR and SUR were limited/inhibited by $\mathrm{pH}$ and temperature, and not due to styrene concentrations (19.3-170.6 $\mathrm{mg} \mathrm{l}^{-1}$ ). 
a
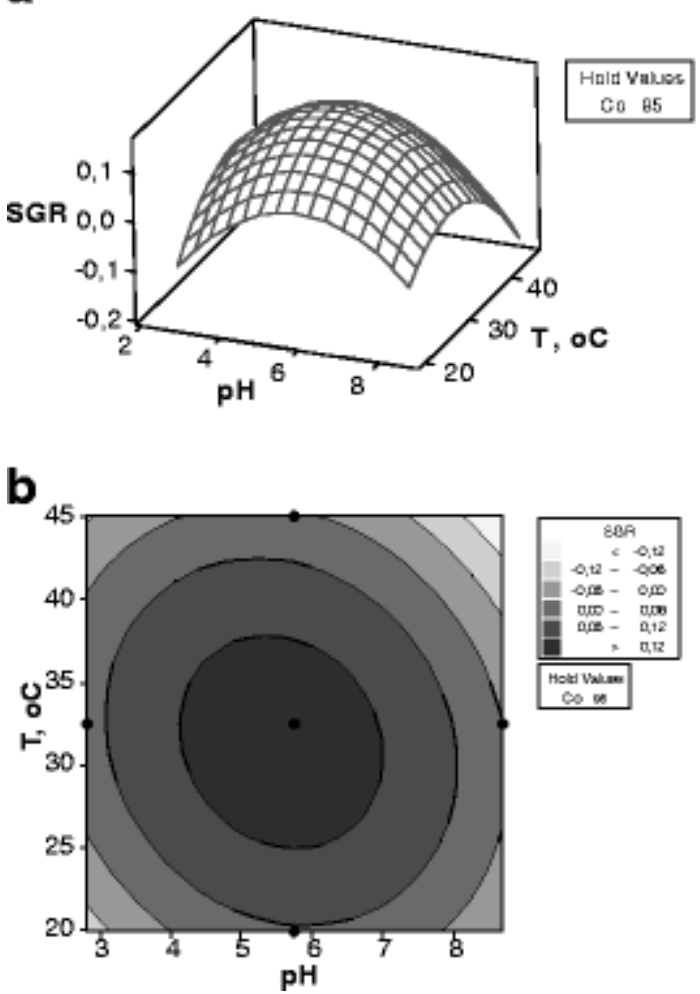

C

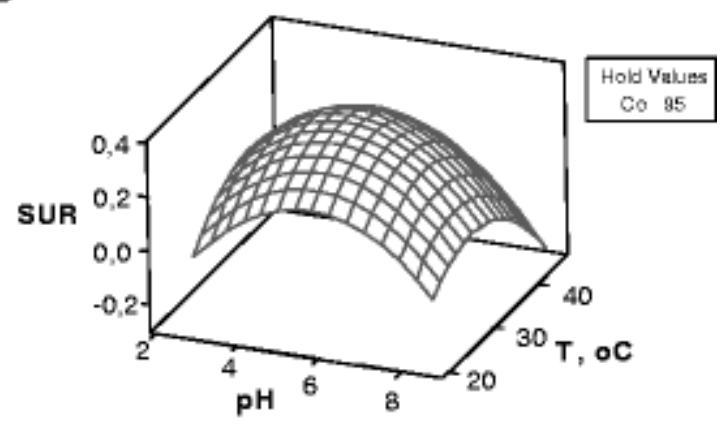

d

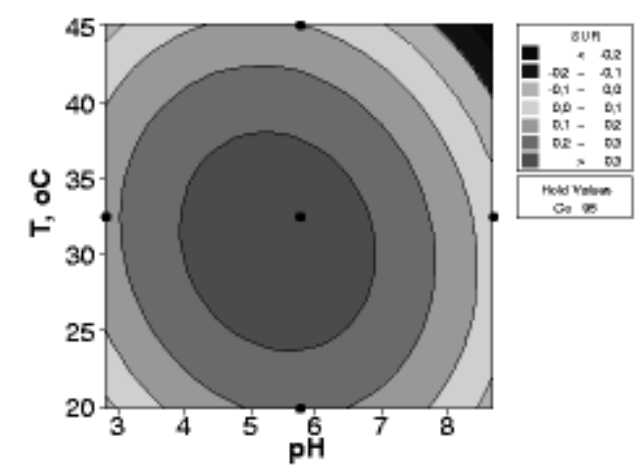

Fig. 4

Response surface curves and contour plots for SGR (a, b) and SUR (c, d) during styrene biodegradation. Effect of $\mathrm{pH}$ and temperature (styrene concentration was kept constant at $95 \mathrm{mg} \mathrm{l}^{-1}$ )
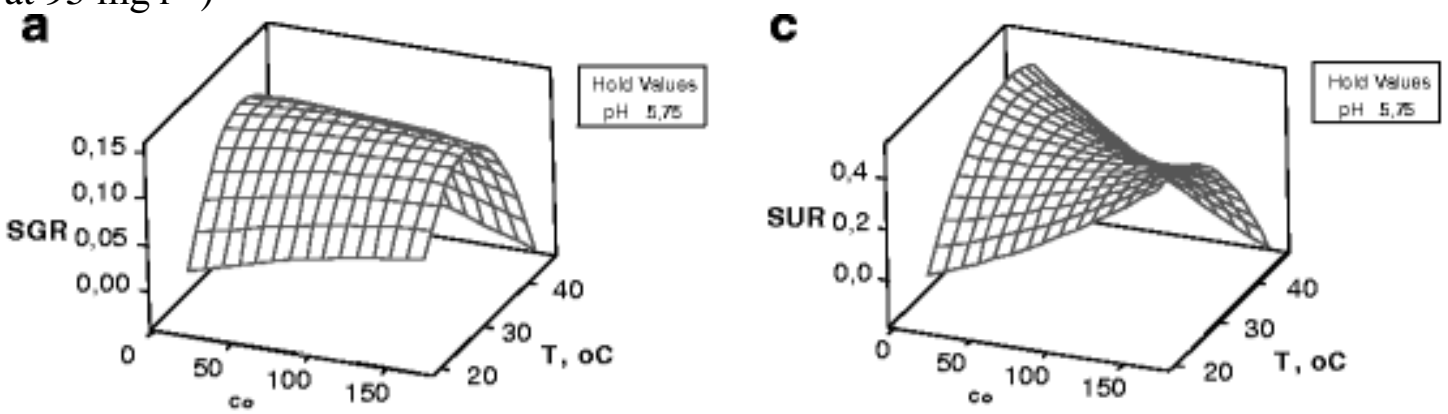

b

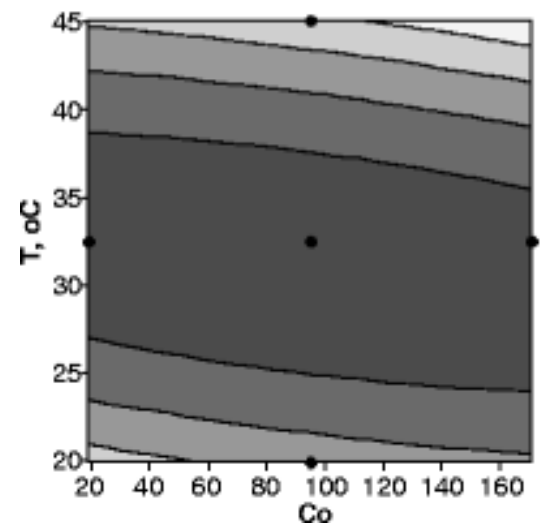

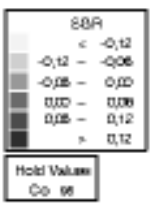

d

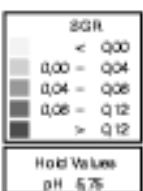

Fig. 5

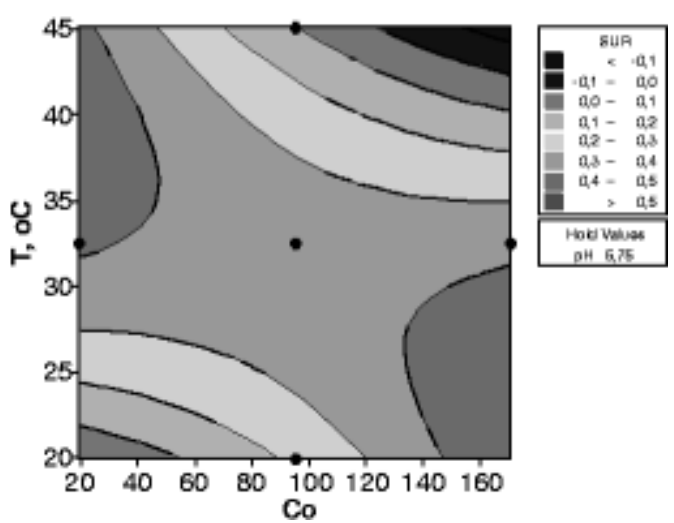

Response surface curves and contour plots for SGR (a, b) and SUR (c, d) during styrene biodegradation. Effect of styrene concentration $\left(\mathrm{C}_{\mathrm{o}}\right)$ and temperature ( $\mathrm{pH}$ was kept constant at 5.75) 

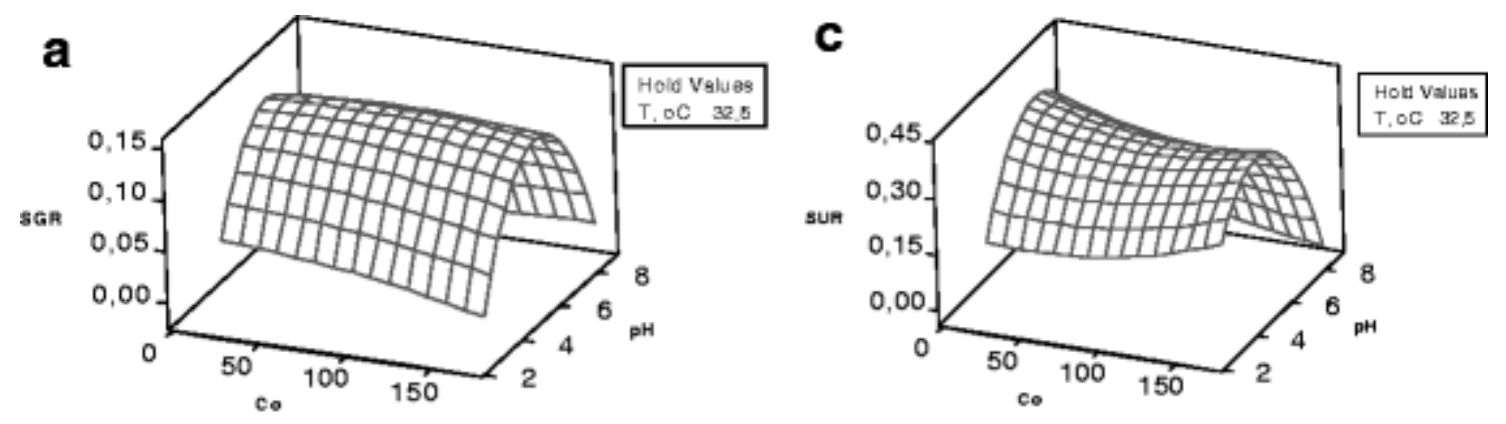

b
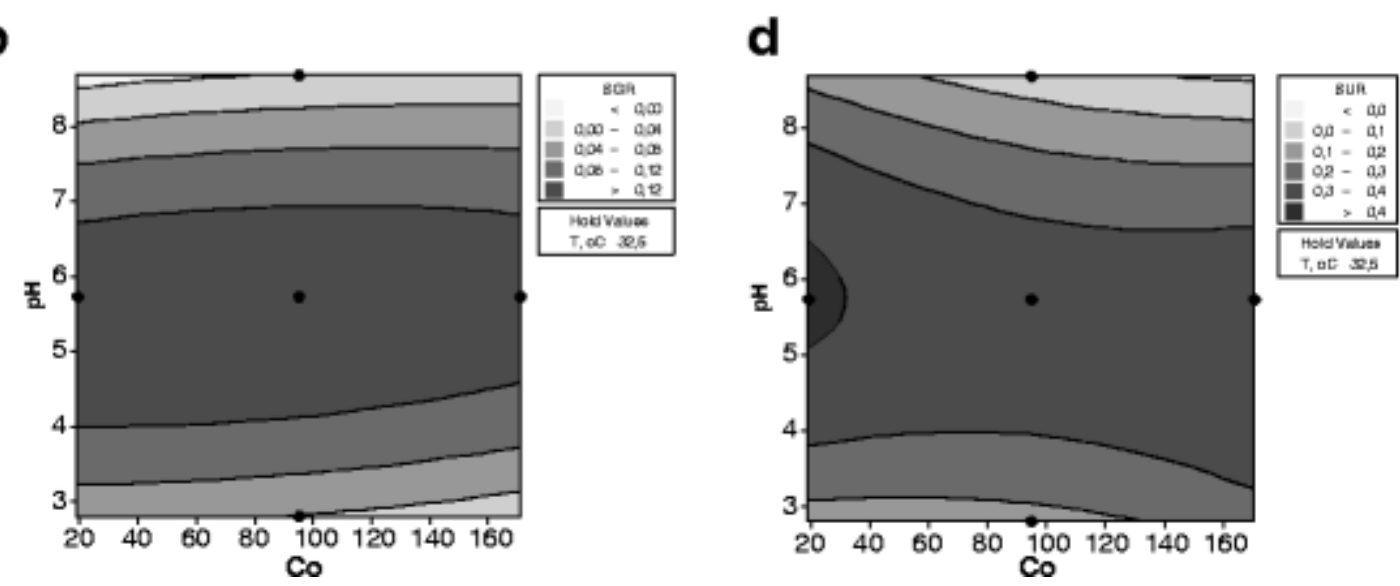

Fig. 6

Response surface curves and contour plots for SGR (a, b) and SUR (c, d) during styrene biodegradation. Effect of styrene concentration $\left(\mathrm{C}_{\mathrm{o}}\right)$ and $\mathrm{pH}$ (temperature was kept constant at $32.5^{\circ} \mathrm{C}$ )

The model Eqs. (ㅁ) and (ㅁ) were optimized using the multistage Monte Carlo optimization technique, as explained elsewhere [37]. The optimal values, first obtained in coded values of the individual parameters, were then converted to uncoded units using Eq. (2). The optimal values for achieving high values of the response variables are shown here; (1) SGR, $\mathrm{C}_{\mathrm{o}}=89.1 \mathrm{mg} \mathrm{l}^{-1}, \mathrm{pH}=5.438$, and $\mathrm{T}=31.48^{\circ} \mathrm{C}$ and (2) SUR, $\mathrm{C}_{\mathrm{o}}$ $=69.2 \mathrm{mg} \mathrm{l}^{-1}, \mathrm{pH}=5.48$, and $\mathrm{T}=32.45^{\circ} \mathrm{C}$, respectively. The optimal values obtained here are the resultants of the optimal values characteristic for Exophiala sp. using styrene as the carbon and energy source. Under these conditions, the predicted SGR and SUR were $0.15 \mathrm{~h}^{-1}$ and $0.362 \mathrm{mg}$ styrene $\mathrm{mg}^{-1}$ biomass $\mathrm{h}^{-1}$, respectively, which are comparable to the values observed during runs 15-20 (centerpoint).

Furthermore, the factors were optimized for maximizing the values for both SGR and SUR, so as to get one set of operating conditions. The desirability function $d_{i}\left[y_{i}{ }^{\wedge}\right]$ is given by;

$$
d_{i}\left[\widehat{y}_{i}\right]=\left\{\left(\frac{y_{i}-{ }^{o} L_{i}}{T_{i}-{ }_{1} L_{i}}\right)^{r_{i}}\right\} \begin{gathered}
\hat{y}<t L_{i} \\
L_{i} \leq \hat{y} \leq T_{i} \\
\hat{y}>T_{i}
\end{gathered}
$$

(8)

where, $\mathrm{L}$ and $\mathrm{T}$, are the lower and target values of response measured from the experimental data, $\mathrm{y}_{\mathrm{i}}$ is the value of a response predicted by the second-order polynomial equation, and $\mathrm{r}_{\mathrm{i}}$ is the weight of desirability function of a response [요 $\left.\underline{39}\right]$. The target values were set at $\mathrm{SGR}=0.17 \mathrm{~h}^{-1}$ and $\mathrm{SUR}=0.5 \mathrm{mg}$ styrene $\mathrm{mg}^{-1}$ biomass $\mathrm{h}^{-1}$, respectively. The overall desirability function was calculated as; 
(9)

$$
D=\left\{\prod\left(d_{i}^{w i}\right)\right\}^{1 / w}
$$

where, $d_{i}$ is individual desirability for the $i^{\text {th }}$ response, $W_{i}$ is the importance of the $i^{\text {th }}$ response, and $\mathrm{W}$ is equal to $\Sigma \mathrm{W}_{\mathrm{i}}$.

The desirability function test in this multiple response optimization method, i.e., optimizing SGR and SUR simultaneously, shows that the individual desirability values for SGR and SUR were 0.837 and 0.92, and values closer to one indicate the fact that the function increases linearly towards the desired target values of the two responses. The maximum predicted responses were found to be $0.142 \mathrm{~h}^{-1}$ and $0.46 \mathrm{mg}$ styrene $\mathrm{mg}^{-1}$ biomass $\mathrm{h}^{-1}$ for SGR and SUR, respectively. Thus, using the desirability function method, the optimized values of styrene concentration, $\mathrm{pH}$, and temperature were estimated to be $170 \mathrm{mg} \mathrm{l}^{-1}, 5.6$ and $28.2^{\circ} \mathrm{C}$, respectively. These optimized values of $\mathrm{pH}$ and temperature are somewhat closer to the earlier optimized values of these parameters solved using the regression model for SGR and SUR $(\mathrm{pH}=5.48,5.438 ; \mathrm{T}=32.4$, $31.4^{\circ} \mathrm{C}$ ). However, as expected, the Exophiala sp. was shown here to tolerate higher styrene concentrations without inhibition $\left(\sim 170 \mathrm{mg} \mathrm{l}^{-1}\right)$ under well-optimized $\mathrm{pH}$ and temperature conditions.

The SUR values obtained in this study are comparable to other literature reports where similar VOCs have been tested under batch conditions. Jung and Park [무] observed that the bacterial styrene degradation rate increased with an increase in the substrate concentration and then decreased with further increase in styrene concentration beyond $97 \mathrm{mgl}^{-1}$. A maximum degradation rate of $0.16 \mathrm{mg}$ styrene $\mathrm{mg}^{-1}$ protein $\mathrm{h}^{-1}$ was reported. Cox et al. [ $\underline{9}$ ] reported a styrene degradation rate of $21 \mu \mathrm{g}$ styrene $\mathrm{mg}^{-1}$ protein $\min ^{-1}$ when batch biodegradation tests were conducted using the fungus E. jeanselmei, and substrate inhibition was observed at a styrene concentration of $3.25 \mathrm{~g} \mathrm{~m}^{-3}$ in gas phase at $25^{\circ} \mathrm{C}$ and $\mathrm{pH}$ 5.7. Estévez et al. [] ] tested toluene removal by two fungal isolates and reported a toluene biodegradation rate of 16 and $37 \mu \mathrm{g}$ toluene $\mathrm{mg}^{-1}$ biomass $\min ^{-1}$ for Paecilomyces variotii and E. oligosperma, respectively.

\section{GC/MS and LC/MS Analysis of Styrene Metabolites}

The initial styrene concentration used $\left(170.6 \mathrm{mgl}^{-1}\right)$, $\mathrm{pH}$, and temperature of the cultures (5.75 and $32.5^{\circ} \mathrm{C}$, respectively) were based on the results presented above. Metabolites produced from styrene biodegradation (styrene oxide, phenylacetaldehyde, phenylacetic acid, 2-hydroxyphenylacetic acid) were determined after $6,12,24,48,72$, 96, and 120 h, respectively, of batch Exophiala sp. incubation (Figs. $\underline{7}$ and $\underline{8}$ ). Among the metabolites detected, styrene oxide appeared only at the very early stage of incubation. Analyte recovery was found to be strongly dependent on incubation time because styrene oxide is an unstable compound in the presence of peroxides or water [41], and hence it is easily converted into other oxidized products. The same compounds were also found in cultures of E. jeanselmei as reported by Cox et al. [42]. The results from this study suggest that this particular strain of Exophiala degrades styrene via phenylacetic acid, involving initial oxidation of the vinyl side chain (Fig. ), as proposed earlier also for another similar fungus, E. jeanselmei [느]. 


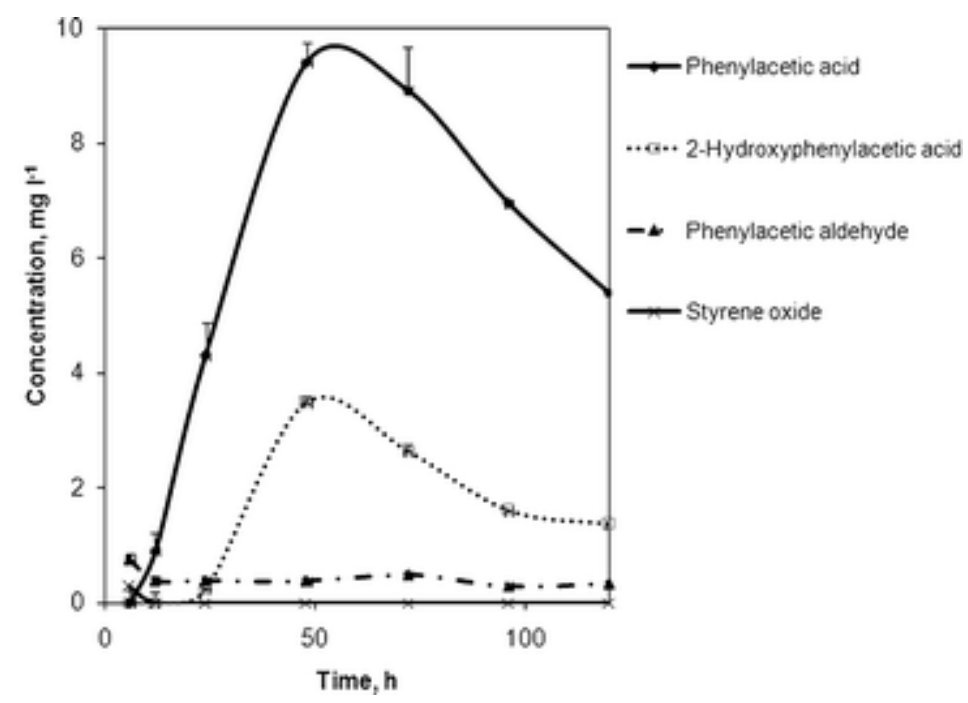

Fig. 7

Metabolites of styrene formed by Exophiala sp. during $120 \mathrm{~h}$ culturing on mineral salt medium

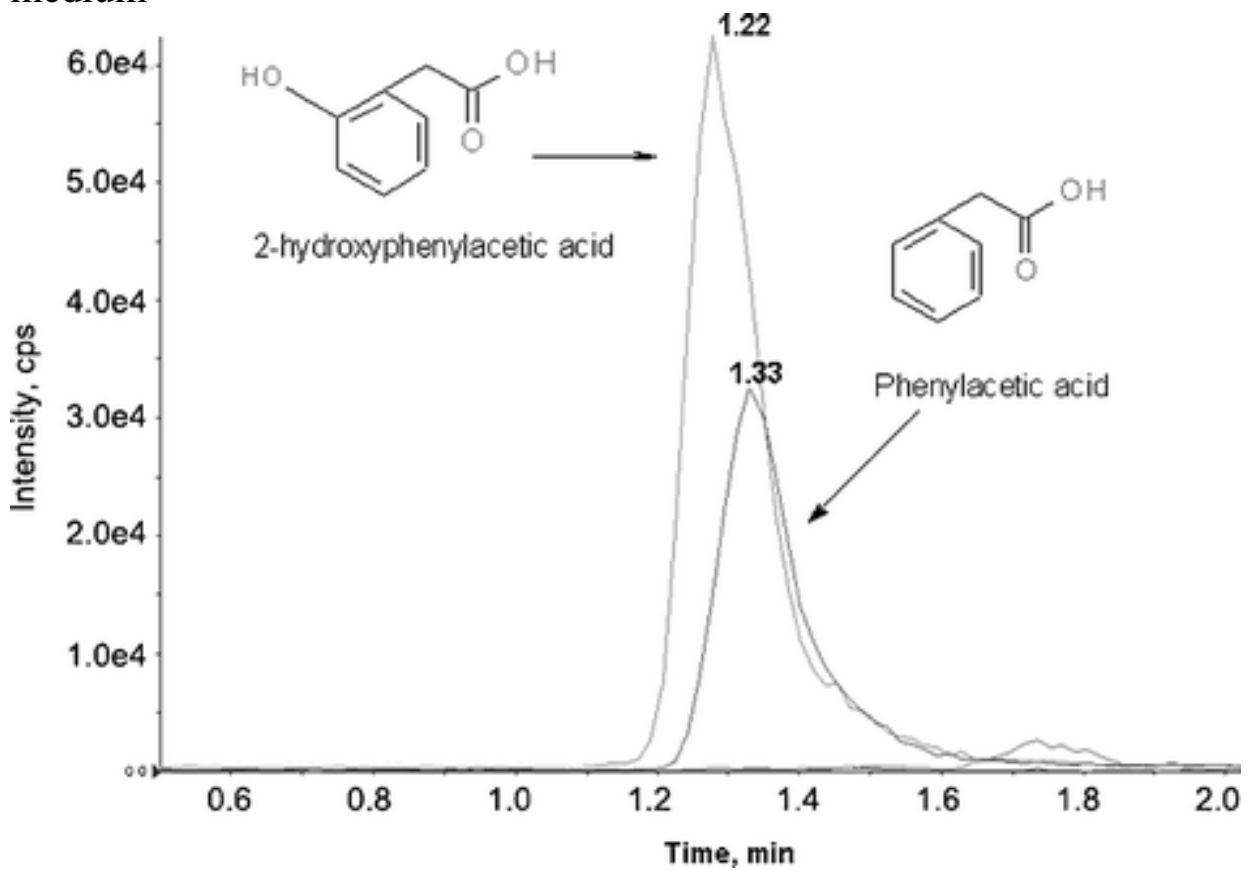

Fig. 8

HPLC-ESI-MS/MS chromatogram (MRM) of styrene metabolites in Exophiala sp. culture after $48 \mathrm{~h}$ of incubation on mineral salt medium 


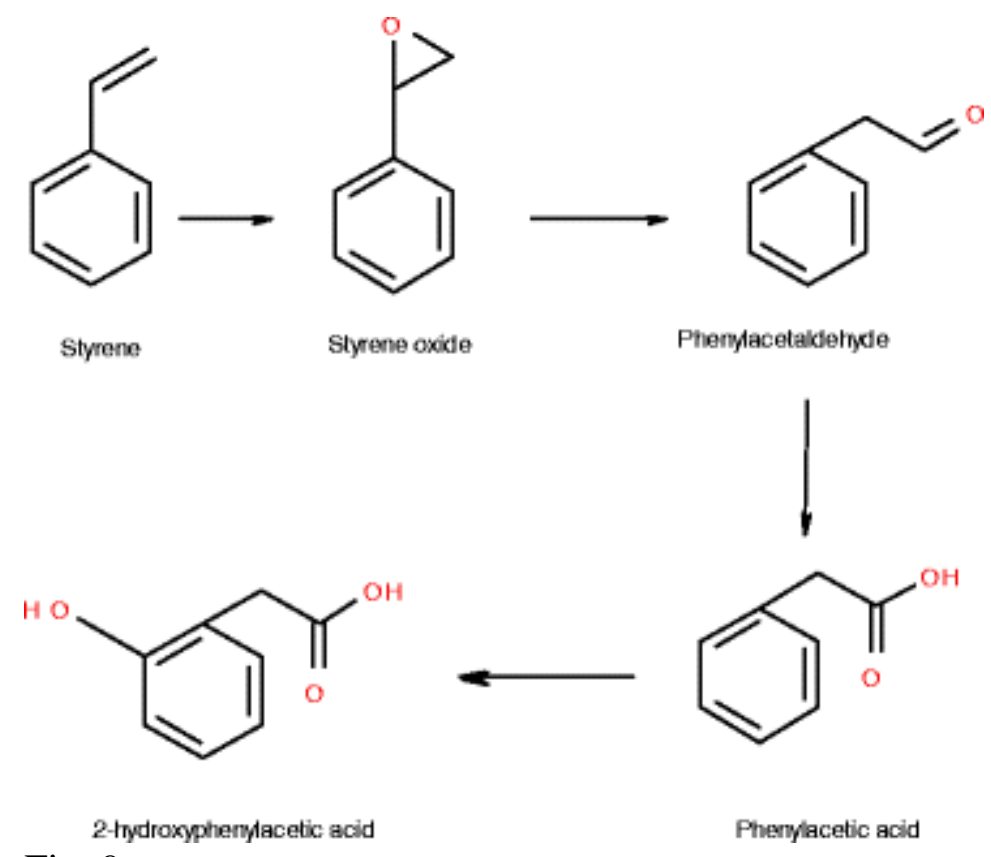

Fig. 9

Proposed route of styrene degradation in Exophiala sp. on mineral salt medium

Styrene Effect on Fatty Acids Profile of E. oligosperma

Studies were performed to study the effect of styrene on the phospholipids of the Exophiala sp. which are considered to be highly sensitive to alterations in the state of the physical environment [43]. As control, glucose $\left(200 \mathrm{mg} \mathrm{l}^{-1}\right)$ was used as nontoxic substrate in the experiments. Growth of the Exophiala sp. in the presence of styrene or styrene + glucose was delayed compared to the control culture with glucose only (Fig. 10). The analyses of fungal phospholipids were done at the early stationary phase of growth, by withdrawing culture samples after $72 \mathrm{~h}$. The determination of the membrane fatty acids (Fig. 11) showed that almost $90 \%$ of the lipids in Exophiala sp. contained three types of fatty acids: saturated (16:0 palmitic; 18:0 stearic), monounsaturated (18:1 oleic and poly-unsaturated; 18:2 linoleic). Other fatty acids (14:0 myristic, 15:0 pentadecanoic, 16:1 7-hexadecenoic, 20:0 arachidic, 24:0 lignoceric) were only detected in small amounts. The dominant content of palmitic acid (16:0), oleic acid (18:1), linoleic acid (18:2) was also noticed in a pathogenic E. jeanselmei strain cultured in submerged minimal medium with glucose [44]. Growth of Exophiala sp. on styrene resulted in changes in the phospholipids fatty acids profile. Supplementation of the growth medium with styrene caused an increase in the membrane fatty acids unsaturation index (Table $\underline{5}$ ). An increase by a factor of 2 of the linoleic acid concentration in the Exophiala sp. exposed to styrene (14-27\%, respectively, in the control and with styrene; Fig. $\underline{11}$ ) is consistent with literature observations [20], where linoleic acid was present in toluene grown cells but not in succinate grown cells of Burkholderia cepacia G4. Linoleic acid played an important role in the resistance of microorganisms to other toxic compounds. In another study, it was observed that Saccharomyces cerevisiae cultivated in the presence of linoleic acid was more tolerant to ethanol than cells grown in the presence of oleic acid [45]. 


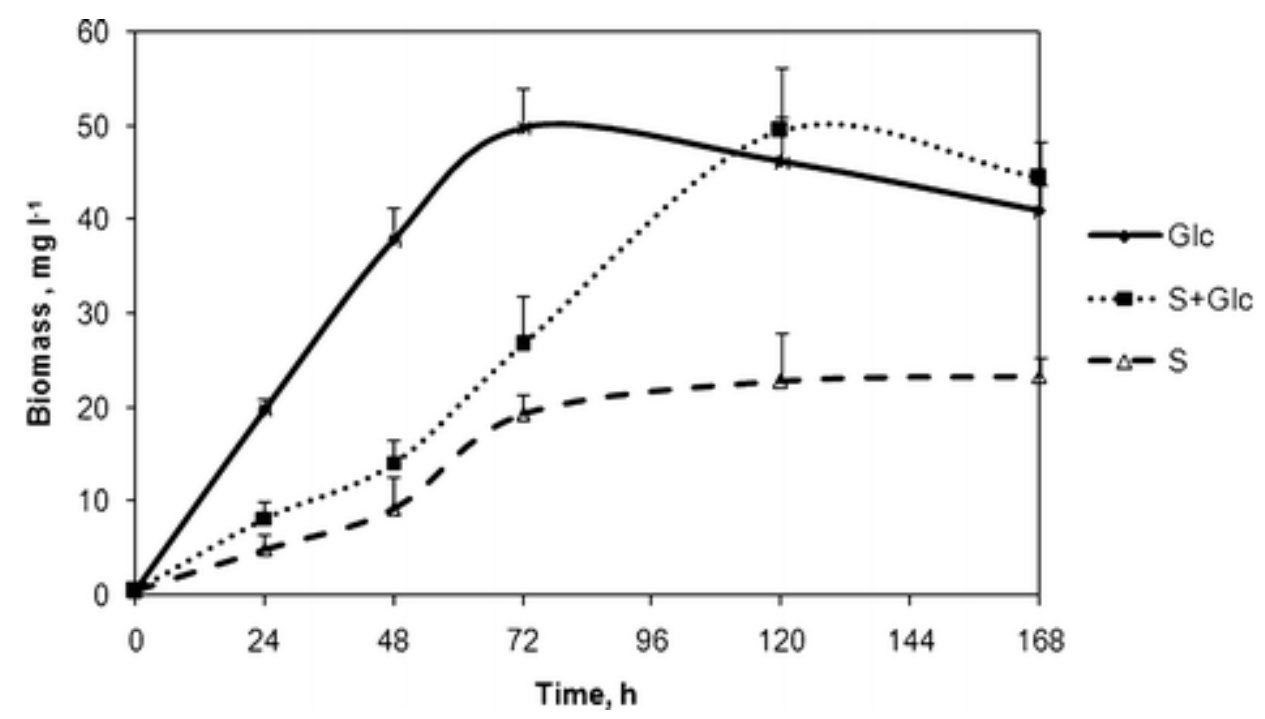

Fig. 10

Growth of Exophiala sp. with styrene (S) and/or glucose (Glc) as a sole source of carbon and energy

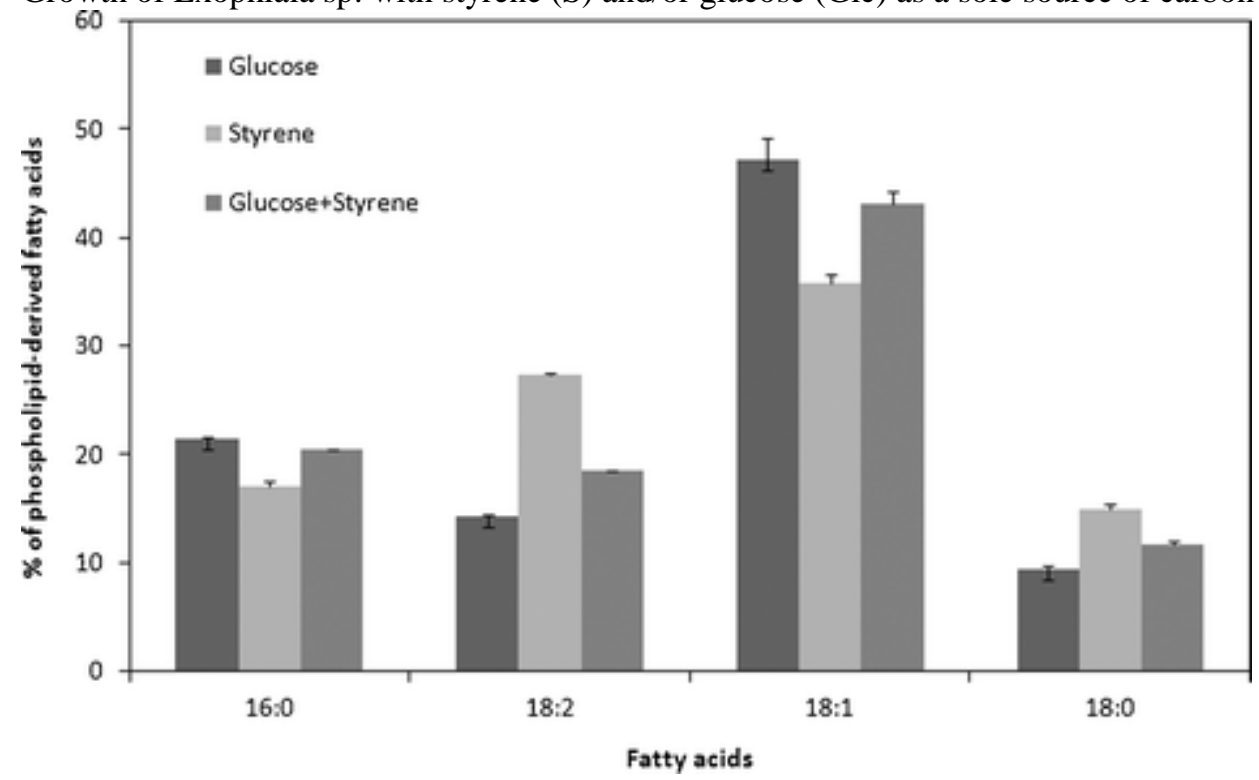

Fig. 11

Composition of the phospholipid-derived fatty acids predominant in Exophiala sp. in biomass withdrawn from the early stationary phase of culture growth, in a mineral salt medium supplemented with either glucose, styrene, or glucose + styrene. All values are means of triplicates

Table 5

Ratio of saturated to unsaturated phospholipids-derived fatty acids in the early stationary phase of growth of Exophiala sp. in mineral medium

\begin{tabular}{|l|l|}
\hline Carbon source & Double bond index \\
\hline Glucose & 2.45 \\
\hline Styrene & 2.81 \\
\hline Styrene + glucose & 2.49 \\
\hline
\end{tabular}

The change in microbial lipid composition in response to membrane-active compounds, such as hydrocarbons, is a well-documented phenomenon $[\underline{11}, \underline{20}]$. Due to the hydrophobic character of hydrocarbons, the primary site of their toxic action is the 
membrane [45]. However, contrary to the above data concerning the adaptation mechanism of microbial cells to toluene [11], no information is available on the adaptation of microorganisms to styrene. From this study, it appears that the phospholipids-derived fatty acids profile of Exophiala sp. was affected by styrene, although the changes were less drastic than those observed in presence of toluene. The increase in the content of unsaturated fatty acids, which results in a higher fluidity of the membrane, can also be induced by polar solvents such as ethanol, acetone, dimethyl sulfoxide, among others, which are miscible with water [45]. Conversely, the pollutant used in this work (styrene), is a relatively nonpolar compound. From the point of view of a significant increase in linoleic acid (18:2) in the mycelium of Exophiala sp., it can be assumed that membrane-bound $\Delta 12$ fatty acid desaturase, which is responsible for the biotransformation of oleic acid (18:1) to linoleic acid (18:2), might have been stimulated [46]. Our results demonstrate for the first time that a strain of Exophiala sp. exposed to styrene shows changes in its fatty acid profile. Based on such observation, it can be suggested that an increasing amount of linoleic acid (18:2) may be involved in maintaining optimal lipid ordering in the presence of styrene.

Further research directions in this field would be targeted towards using the optimized conditions from batch experiments and perform continuous experiments using gasphase styrene, in novel bioreactor configurations such as one and two liquid-phase bioreactors (continuous stirred tank bioreactors and biotrickling filters), and testing the ability of the Exophiala sp. to remove mixtures of gas-phase pollutants and identify the interaction patterns of pollutant removal. Once these molecular to macroscale interactions are understood from continuous experiments, it is also possible to formulate mathematical models that can represent the influence of complex, interacting variables such as multipollutant diffusion/absorption, reaction kinetics, and thermodynamic contributions on the performance parameters of these bioreactors, namely elimination capacity and removal efficiency.

\section{Conclusions}

The present work offers a comprehensive study on the effects of concentration, $\mathrm{pH}$, and temperature on the biodegradation of styrene using the fungus Exophiala sp. The results show that styrene in industrial effluents could be treated with high removal efficiencies $(100 \%)$. The main effects due to $\mathrm{pH}(\mathrm{F}$ statistics $=14.08, \mathrm{P}<0.05)$ and temperature ( $\mathrm{F}$ statistics $=22.05, \mathrm{P}<0.05)$ appeared to be more significant in affecting the SGR, than the main effects due to styrene concentration, suggesting that fungal growth was not inhibited by styrene concentrations between 19.3 and $170.6 \mathrm{mg} \mathrm{l}^{-1}$, but due to the interactions between $\mathrm{pH}$ and temperature. SGR and SUR values were $0.16 \mathrm{~h}^{-1}$ and $0.439 \mathrm{mg}$ styrene $\mathrm{mg}^{-1}$ biomass $\mathrm{h}^{-1}$, respectively, at the following experimental conditions: $\mathrm{C}_{\mathrm{o}}=19.3 \mathrm{mg} \mathrm{l}^{-1}, \mathrm{pH}=5.75$, and $\mathrm{T}=32.5^{\circ} \mathrm{C}$. In addition to response surface optimization, the desirability function method was also used to optimize both responses simultaneously, i.e., SGR and SUR, and their individual desirability values were 0.837 , and 0.92 , respectively. The fungal strain degraded styrene via phenylacetic acid, involving initial oxidation of the vinyl side chain. Additionally, a change in the fatty acids profile of the culture was also observed. It can be suggested that the resistance of Exophiala sp. to styrene is associated with an increasing amount of linoleic acid (18:2) in the fungus. 


\section{Acknowledgments}

The authors thank the Spanish Ministry of Education and Science (Project CTQ200628335-E) and the Polish Ministry of Science and Higher Education (Grant no. 31/HIS/2007/02) for financial support. Eldon R. Rene thanks the Spanish Ministry of Science and Innovation for his postdoctoral research contract (JCI-2008-03109).

References 1 .

Agency for Toxic Substances and Disease Registry (ATSDR). (1992). Toxicological profile for styrene. Atlanta, GA, USA: ATSDR.

2.

Kennes, C., Rene, E. R., \& Veiga, M. C. (2009). Journal of Chemical Technology and Biotechnology, 84, 1419-1436.

3.

Abubackar, H. N., Veiga, M. C., \& Kennes, C. (2011). Biofuels Bioproducts and Biorefining (BioFPR), 5, 93-114.

4.

Sielicki, M., Focht, D. D., \& Martin, J. P. (1978). Applied and Environmental Microbiology, 35, 124-128.

5.

Hartmans, S., van der Werf, M. J., \& de Bont, J. A. M. (1990). Applied and Environmental Microbiology, 56, 1347-1351.

6.

Braun-Lüllemann, A., Majcherczyk, A., \& Hüttermann, A. (1997). Applied Microbiology and Biotechnology, 47, 150-155.

7.

Kennes, C., \& Veiga, M. C. (2004). Journal of Biotechnology, 30, 305-319.

8.

Estévez, E., Veiga, M. C., \& Kennes, C. (2005). Journal of Industrial Microbiology and Biotechnology, 32, 33-37.

9.

Cox, H. H. J., Moerman, R. E., van Baalen, S., van Heiningen, W. N., Doddema, H. J., \& Harder, W. (1997). Biotechnology and Bioengineering, 53, 259-266.

10.

Rene, E. R., Veiga, M. C., \& Kennes, C. (2010). Chemosphere, 79, 221-227.

11.

Fang, J., Lovanh, N., \& Alvarez, P. J. (2004). Water Research, 38, 2529-2536. 12.

Loffhagen, N., Härtig, C., \& Babel, W. (2004). Bioscience, Biotechnology, and Biochemistry, 68, 317-323.

13.

Bernat, P., \& Długoński, J. (2007). International Biodeterioration and Biodegradation, 60, 133-136.

14.

Słaba, M., Szewczyk, R., Bernat, P., \& Długoński, J. (2009). The Science of the Total Environment, 407, 4127-4133.

15.

Bernat, P., Słaba, M., \& Długoński, J. (2009). Current Microbiology, 59, 315-320.

16.

Ravikumar, K., Pakshirajan, K., Swaminathan, T., \& Balu, K. (2005). Chemical Engineering Journal, 105, 131-138. 
17.

Wu, S., Yu, X., Hu, Z., Zhang, L., \& Chen, J. (2009). Journal of Environmental Sciences, 21, 1276-1283.

18.

Kennes, C., Cox, H. H. J., Doddema, H. J., \& Harder, W. (1996). Journal of Chemical Technology and Biotechnology, 66, 300-304.C

19.

Cox, H. H. J., Houtman, J. H. M., Doddema, H. J., \& Harder, W. (1993). Biotechnology Letters, 15, 737-742.

20.

Fang, J., Barcelona, M. J., \& Alvarez, P. J. (2000). Applied Microbiology and Biotechnology, 54, 382-389.

21.

Gajewska, E., Bernat, P., Długoński, J., \& Skłodowska, M. (2012). Journal of Agronomy and Crop Science, 198, 286-294.

22.

Rajasekaran, A. K., \& Maheshwari, R. (1993). Journal of Biosciences, 8, 345-354.

23.

Mohammad, B. T., Veiga, M. C., \& Kennes, C. (2007). Biotechnology and Bioengineering, 97, 1423-1438.

24.

Jin, Y., Guo, L., Veiga, M. C., \& Kennes, C. (2007). Biotechnology and Bioengineering, 96, 433-443.

25.

Montes, M., Veiga, M. C., \& Kennes, C. (2010). Bioresource Technology, 101, 94939499.

26.

Wang, C., Xi, J.-Y., Hu, H.-Y., \& Wen, X.-H. (2008). Biomedical and Environmental Sciences, 21, 474-478.

27.

Estévez, E., Veiga, M. C., \& Kennes, C. (2005). Applied Microbiology and Biotechnology, 67, 563-568.CrossRef

28.

Yarmoff, J. J., Kawakami, Y., Yago, T., \& Maruo, H. (1988). Journal of Fermentation Technology, 66, 305-312.

29.

Bhattacharya, S. S., \& Banerjee, R. (2008). Chemosphere, 73, 81-85.

30.

de Hoog, G. S., Guarro, J., Gene, J., \& Figueras, M. J. (2000). Atlas of clinical fungi, second (Vol. 1). Utrecht, The Netherlands: Centraalbureau voor Schimmelcultures. 31.

Dix, N. J., \& Webster, J. (1995). Fungal ecology. London: Chapman \& Hall. 32.

Segurola, J., Allen, N. S., Edge, M., \& Mahon, A. M. (1999). Progress in Organic Coating, 37, 23-37.

33.

Li, Y., Cui, F., Liu, Z., Xu, Y., \& Zhao, H. (2007). Enzyme and Microbial Technology, 40, 1381-1388. 
34.

Tanyildizi, M. S., Özer, D., \& Elibol, M. (2005). Process Biochemistry, 40, 2291-2296. 35.

Sahoo, N. K., Pakshirajan, K., \& Ghosh, P. K. (2010). International Biodeterioration and Biodegradation, 64, 474-480.

36.

Myers, R. H., Montgomery, D. C., \& Anderson-Cook, M. (2009). Response surface methodology: process and product optimization using designed experiments (3rd ed.). NJ: Wiley.

37.

Cooney, D. O. (1999). Adsorption design for wastewater treatment. New York: CRC.

38.

Harrington, E. C. (1965). Industrial Quality Control, 21, 494-498.

39.

Derringer, G., \& Suich, R. (1980). Journal of Quality Technology, 12, 214-219.

40.

Jung, I. G., \& Park, C. H. (2005). Chemosphere, 61, 451-456.CrossRef

41.

Toda, H., \& Itoh, N. (2012). Journal of Bioscience and Bioengineering, 113, 12-19.

42.

Cox, H. H. J., Faber, B. W., Van Heiningen, W. N., Radhoe, H., Doddema, H. J., \& Harder, W. (1996). Applied and Environmental Microbiology, 62, 1471-1474.

43.

Dercová, K., Certık, M., Malová, A., \& Sejáková, Z. (2004). International Biodeterioration and Biodegradation, 54, 251-254.

44.

Sassaki, G. L., Czelusniak, P. A., Vicente, V. A., Zanata, S. M., Souza, L. M., Gorin, P. A., et al. (2011). International Journal of Biological Macromolecules, 48, 177-182.

45.

Sikkema, J., de Bont, J. A., \& Poolman, B. (1995). Microbiological Reviews, 59, 201222.

46.

Certik, M., \& Shimizu, S. (1999). Journal of Bioscience and Bioengineering, 87, 1-14. 